\title{
Allocentric and egocentric spatial information processing in the hippocampal formation of the behaving primate
}

\author{
JANET D. FEIGENBAUM and EDMUND T. ROLLS \\ University of Oxford, Oxford, England
}

\begin{abstract}
To investigate how space is represented in the primate hippocampus, the activity of single neurons was recorded in the hippocampus of behaving macaque monkeys. Neurons that responded differently according to the position on a screen in which a stimulus was shown when the monkey had to remember the stimulus and its position were analyzed for their spatial fields. By mov. ing the monkey into different positions relative to the screen, and the screen to different positions in the room, it was possible to separate neuronal representations in egocentric coordinates (i.e., defined relative to the monkey's body axis) from representations in local allocentric coordinates (i.e., defined relative to the frame of reference provided by the screen on which the stimuli were displayed) and from representations in absolute allocentric coordinates (i.e., defined relative to absolute position in the room). It was found that $44 \%$ of the spatial neurons analyzed in these experiments responded in relation to space defined by the local frame of reference and not in relation to space defined in egocentric or in absolute allocentric coordinates. Two percent of the neurons responded in relation to the absolute position of a stimulus in the room (in absolute allocentric coordinates). Ten percent responded in relation to egocentric coordinates. Forty-four percent responded to a combination of the different coordinate systems investigated, including $23 \%$ that were shown to include an absolute allocentric component. Thus the main finding was that in the primate hippocampus many spatial cells (69\% of those analyzed) responded in relation to allocentric coordinates, in many cases in relation to a local frame of reference and in some cases in relation to the absolute position of the stimulus in the room. In Experiment 2, the possibility of retinotopic encoding was investigated by presenting test spots of light at different positions relative to a fixation spot, and in different blocks of trials by moving the fixation spot to different positions on the screen. It was found that very few hippocampal cells were responsive in this task, and that for the cells that did respond, the encoding was not retinotopic. These results are consistent with the scarcity of egocentric encoding cells, and the preponderance of allocentric encoding, found in Experiment 1. In Experiment 3, it was found that relatively many hippocam. pal neurons (17\%) responded differently according to the spatial position being fixated on the screen, in a task in which a small fixation spot appeared on each trial in a different position on the screen. This result confirms that hippocampal spatial cells do not encode spatial information using retinotopic coordinates, shows that it is sufficient for many of these hippocampal spatial neurons to respond that the monkey fixate particular positions in space, and is consistent with the finding in Experiment 1 that the preponderant type of encoding used by these hippocampal spatial neurons is allocentric.
\end{abstract}

Bilateral damage to the temporal lobe in humans can cause anterograde amnesia (Milner, 1972; Scoville \& Milner, 1957). A number of structures are damaged, including structures of the hippocampal formation. Experimental investigations have been performed to determine which structures are crucial in producing the amnesia, and to analyze the neural bases of the different types of amnesia

This work was supported by the Medical Research Council. Janet D. Feigenbaum was a Marshall Scholar. We thank P. M. B. Cahusac for research support. Janet $D$. Feigenbaum is now in the Department of Anatomy, University College London, Gower St., London WCIE 6BT, England. Correspondence concerning this article should be addressed to Edmund T. Rolls, University of Oxford, Department of Experimental Psychology, Oxford OX1 3UD, England.
(Squire \& Zola-Morgan, 1988). In analyses of the way in which the hippocampus could contribute to a memory deficit in primates (for review, see Rolls, 1990), it has been shown that tasks that are particularly affected by damage to the hippocampus or fornix in the primate include nonspatial tasks such as recognition memory (Gaffan, 1974, 1977; Gaffan, Gaffan, \& Harrison, 1984; Gaffan \& Weiskrantz, 1980; Owen \& Butler, 1981; ZolaMorgan \& Squire, 1985), as well as spatial tasks such as memory of where in space an object has been seen before (Gaffan \& Saunders, 1985; Parkinson, Murray, \& Mishkin, 1988; Smith \& Milner, 1981), utilization of spatial cues to determine which object to select (Gaffan \& Harrison, 1989a), and learning where to make a spatial response (e.g., in a conditional spatial response task- 
see Gaffan, Saunders, et al., 1984; Rupniak \& Gaffan, 1987-and in man, Petrides, 1985). In analyses of the functions of the hippocampus in the rat, it has been suggested that rats with hippocampal damage have an impaired ability to create a map of space, in that they are impaired in running correctly on an eight-arm maze, or in swimming correctly to a submerged platform-situations in which the rats must use extramaze cues to determine their position in space (Barnes, 1988; Morris, Garrud, Rawlins, \& O'Keefe, 1982; O'Keefe \& Nadel, 1978). There is evidence that some hippocampal neurons in the rat fire when the rat is in a particular place in an environment (McNaughton, Barnes, \& O'Keefe, 1983; O'Keefe, 1979, 1983).

In order to analyze neurophysiologically how the primate hippocampus might be involved in spatial function, and in particular in memory for where in space objects have been seen before (see above), Rolls et al. (1989) recorded the responses of hippocampal neurons in macaques, using a serial multiple object-place memory task requiring a memory for in which of 4 or 9 positions on a video monitor a given object had appeared previously. (This task is known to be impaired by fornix section; see Gaffan \& Saunders, 1985). It was found that $9.3 \%$ of neurons recorded in the hippocampus and parahippocampal gyrus had spatial fields in this and related tasks, and that $2.4 \%$ of the neurons responded to a combination of spatial information and information about the object seen (i.e., they responded more, the first time a particular object was seen in any position). This investigation showed that not only is spatial information processed by the primate hippocampus, but it can be combined with information about which stimuli have been seen previously (Rolls et al., 1989).

The previous investigation showed that some hippocampal neurons in primates have spatial fields, but no attempt was made to investigate the type of spatial representation or coordinate system present in the primate hippocampus. In the study described here, we investigated whether the spatial fields are mapped in egocentric or in allocentric coordinates. This was investigated by finding a neuron with a spatial response and then moving the monitor screen and the monkey relative to each other. If the neuron responded to stimuli in the same position relative to the monkey's body axis when the screen was moved and/or the monkey was rotated or moved to a different position in the laboratory, then these neurons were described as responding in egocentric coordinates. If the neuron responded to the same position on the screen or in the room when the monkey or the screen was rotated or moved to a different position in the laboratory, then the neurons were described as responding in allocentric coordinates. Because neurons that responded to allocentric coordinates were found during the recordings described here, further tests were performed to distinguish between different types of allocentric encoding. In one form of allocentric encoding, the spatial field of the neuron was defined by its position on the monitor screen, and it was independent of the position of the monitor relative to the monkey's body axis and independent of the absolute position of the monkey and the screen in the laboratory. These neurons were called frame-of-reference allocentric (i.e., their fields were defined by the local frame provided by the monitor screen). In the second type of allocentric encoding, the field was defined by its position in the room, and was independent of position relative to the monkey's body axis and to position on the monitor screen. These neurons were called absolute allocentric. The results, which are described here, provide evidence that although some neurons in the hippocampal formation have egocentric spatial fields, similar to those found in other parts of the brain (Andersen, 1987; Sakata, 1985), the majority of neurons in the primate hippocampal formation encode space in allocentric coordinates. A preliminary report of this work has appeared (Feigenbaum, Cahusac, \& Rolls, 1987), and some consistent evidence, together with evidence for hippocampal neurons with auditory spatial responses, has just been reported (Tamura, Ono, Fukuda, \& Nakamura, 1990).

\section{EXPERIMENT 1}

\section{Method}

Pretraining and laboratory setup. All animals were accustomed to the laboratory over a 2- to 3-week period. The monkeys were taught each of the tasks, beginning with the simpler tasks such as the touch task and the operant task, and then they progressed to more complex tasks such as the serial object-place memory task (described below). All of the tasks were performed with stimuli presented on a video monitor, in an open laboratory testing environment. The monkey and the monitor could be moved to different positions in the laboratory. The monkey was exposed to a wide variety of visual cues around the laboratory, which were available to identify his position at any time.

The spatial tasks. One of the spatial tasks performed by the monkeys was identical to the serial object-place memory task described in detail by Rolls et al. (1989). Performance on this task is known to be impaired by damage to the fornix (Gaffan \& Saunders, 1985), and Rolls et al. (1989) have found neurons with spatial responses in monkeys performing this task. Other, simpler, spatial tasks were also performed by the monkeys, since these tasks have been shown to activate spatial neurons in the hippocampus (Rolls et al., 1989).

Serial object-place memory task $(M P L)$. In the serial object-place memory task, the monkey had to remember the positions in which he had previously seen a particular stimulus. On each trial, a stimulus was shown in one of four positions on a video monitor. Each stimulus was shown in each position twice. The first time a stimulus was shown in a particular position (novel condition), the monkey had to avoid licking a tube in front of his mouth, in order to avoid obtaining a taste of saline. The second time the monkey saw the stimulus in a given position (familiar condition), he could lick the tube to obtain fruit juice. For each new stimulus, the computer randomized the order of the positions in which a stimulus was shown, subject to the constraint that the same reinforcement contingency should not be repeated consecutively more than three times. After each stimulus had been shown in each position twice, the computer continued the task with a new stimulus. In a spatial response version of the task, to receive a reward, instead of licking at a tube on positively reinforced (familiar) trials, the monkey was trained to reach and touch the quadrant where a familiar stimulus appeared. The tasks were completely computer-controlled, to ensure that there was 
no influence of the experimenters on the monkey's behavior or on the neuronal activity. The computer switched the stimuli on and off for each trial, and synchronized its data collection so that the stimulus was turned on at the start of the $21 \mathrm{st}$ bin of a peristimulus time histogram. The stimuli were displayed $30 \mathrm{~cm}$ from the monkey on a color video monitor that subtended $12^{\circ}$ at the retina, and they occupied the appropriate quarter of the monitor screen. The stimuli were either junk pseudocolored stimuli digitized from the television, or simple geometric shapes such as boundary curvature descriptors (Schwartz, Desimone, Albright, \& Gross, 1983). The resolution of these images was 256 pixels wide $\times 256$ pixels high, with 256 gray levels or colors. The stimuli were stored on the PDP-11 or Microvax II computer disk ready for random access loading into an AED 512 video framestore. A $0.5-\mathrm{sec}$ signal tone $(400 \mathrm{~Hz})$ preceded the presentation of the stimulus in all tasks, and if the monkey was fixating correctly (to the area at the center of the screen) before the stimulus appeared, he had sufficient time to perform the discrimination and obtain multiple licks of the fruit juice tube during the short $(1.0-\mathrm{sec})$ period in which the stimulus was present. This procedure was designed to ensure fixation of the stimuli (Rolls, Sanghera, \& Roper-Hall, 1979). Recordings made with the search coil method (Judge, Richmond, \& Chu, 1980) confirmed that this procedure resulted in consistent fixation of the stimuli (see below, and see Rolls et al., 1989).

Touch task (TCH). In a simpler spatial response task (TCH), a single image was presented in one of four quadrants on the touchsensitive video screen. The monkey was required to reach forward and touch the quadrant of the screen in which the image appeared. The stimulus was displayed $30 \mathrm{~cm}$ from the monkey on a video monitor that subtended $12^{\circ}$ at the retina, and the image occupied one quarter of the monitor screen. The stimulus was of similar complexity to those used in the MPL task. At the beginning of a TCH trial, a $500-\mathrm{Hz}$ tone was sounded for $0.5 \mathrm{sec}$ to alert the monkey to view the screen. The image was then presented at the offset of the tone and remained on the screen for $1.5 \mathrm{sec}$. When the monkey touched the appropriate location on the screen during the $1.5 \mathrm{sec}$ when the image was present, he received fruit juice from a tube placed directly in front of his mouth. If the monkey failed to touch the screen within the $1.5 \mathrm{sec}$, an error was recorded by the computer, and the monkey did not receive any reward. If the monkey touched a quadrant other than the quadrant in which the stimulus appeared, he received a small amount of aversive saline, and an error trial was again recorded. Thus, this task required the monkey to make a differential spatial response to an image presented in one of four locations on the screen.

Multiple place operant task (MPOP). The multiple place operant task consisted of a simple visual discrimination task with the stimuli presented in a pseudorandom sequence in one of four quadrants on the screen. This task was run using a larger video screen, which subtended $38^{\circ}$ at the retina, and the visual discrimination stimuli occupied the center of one quarter of the screen. The positive discriminandum (S+; a white triangle $5.2^{\circ}$ high and $5.2^{\circ}$ across the base) required that the monkey make a lick response to receive a small amount of fruit juice reward. The negative discriminandum $\left(\mathrm{S}-\right.$; a white square, $\left.5.2^{\circ} \times 5.2^{\circ}\right)$ required the monkey to withhold any response. Both stimuli were of equal luminance. If the monkey made an error by responding to the $S$ - discriminandum, he received a small amount of hypertonic aversive saline.

Spatial manipulations. Three basic manipulations were used to test for the spatial coordinates defined in the introduction. The monkey could be moved while the screen remained in the same place; the screen could be moved while the monkey remained in the same place; or both the screen and the monkey could be moved to a different position in the room.

In the first case-that of moving the monkey and leaving the screen in place-it was possible to test for egocentric spatial encoding (Figure 1). If, when the monkey was moved by half a screen width



Figure 1. Spatial test protocol in which the monkey was moved relative to the screen. The screen, shown on the left, had four (unmarked) quadrants, in one of which a stimulus was shown on each trial. The monkey was initially at position MC (monkey central), If the neuron responded differently to stimuli shown in the four quadrants of the screen, then, on a later block of trials, the monkey could be moved up (MU) or moved down (MD), and the spatial field was reexamined to investigate the spatial coordinates used.

(left or right, up or down), the spatial field moved across the screen so that the spatial field remained in a constant position relative to the monkey's body axis, this provided evidence for egocentric encoding. If the spatial field remained in the same position on the screen when the monkey was moved, this provided evidence that the cell was responding in frame-of-reference or absolute allocentric coordinates, and a further test was performed. To differentiate absolute from frame-of-reference allocentric encoding, both the screen and the monkey were moved to a new position in the room while their positions relative to each other remained constant. If the cell again responded to the same position on the screen, this provided evidence that the cell was firing in relation to frame-of-reference allocentric coordinates, whereas if the cell changed its responses, this provided evidence that the cell was firing to absolute allocentric coordinates.

In the second case, the monkey remained in the same location in the room, and the screen could be moved to one side or the other (Figure 2). In this case, the frame-of-reference allocentric coordinates again remained unchanged, the egocentric coordinates of positions on the screen were altered according to the amount of screen movement, and the absolute allocentric coordinates moved across the screen also. If the cell responded to the same screenbased position, this showed that the cell fired in frame-of-reference (local) allocentric coordinates. If the response of the cell changed so that the cell now responded to another position on the screen, this indicated that the cell was firing in either egocentric coordinates or absolute allocentric coordinates. In this case, the next manipulation was to move both the screen and the monkey to a new location in the room, but to maintain the same relative position of the screen and the monkey as in the initial test. If the cell responded to the same position on the screen in both the standard condition and the screen moved condition, this would imply that the cell was firing in egocentric coordinates. If the cell did not respond in the same way as it did before the screen and monkey were moved to a new position in the room, this indicated that the cell responded in relation to absolute allocentric coordinates.

In the early stages of development of these tests for the different spatial hypotheses, we employed a different testing strategy. In this case, we used the smaller video monitor screen and a simple visual discrimination task (OP). In this simple visual discrimination task, the monkey was presented with a white triangle $(S+)$ to which he could respond, or a white square $\left(S_{-}\right)$from which he was to withhold 

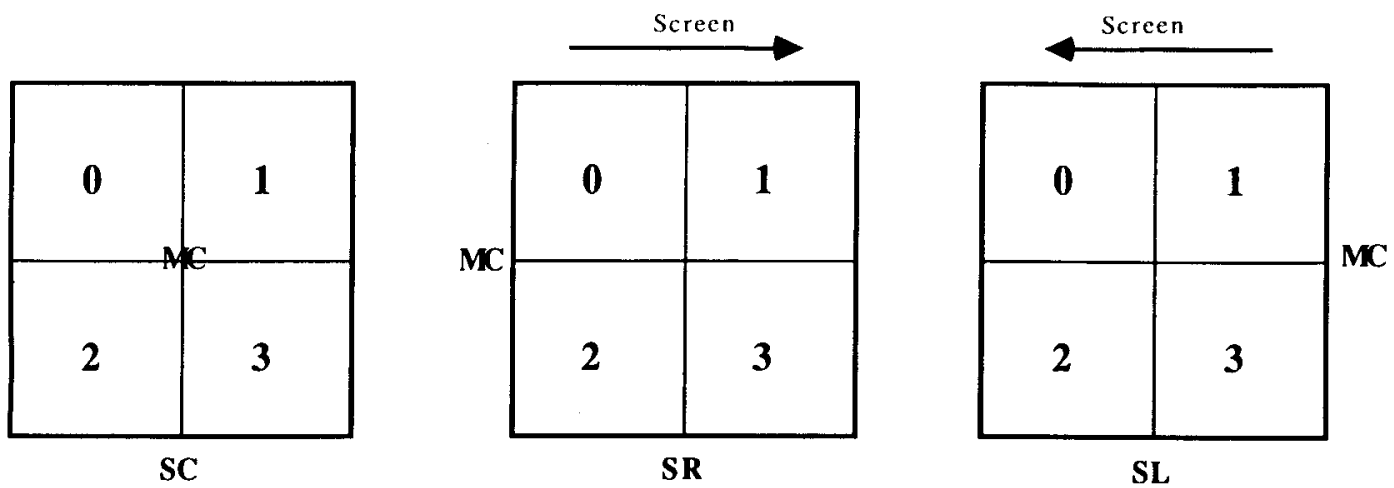

Figure 2. Spatial test protocol in Experiment 1, in which the screen was moved relative to the monkey. The monkey remained in the central position (MC), and the screen was initially in the central position (SC). If the neuron responded differently to stimuli shown in the four quadrants of the screen, then, on later blocks of trials, the screen could be moved right (SR) or left (SL), and the spatial field was reexamined to investigate the spatial coordinates used. For example, Position 0 on the screen in the MC/SC condition is in the same position relative to the monkey (i.e., in egocentric coordinates) as Position 1 in the MC/SL condition.

a response. Both stimuli were $2.3^{\circ} \times 2.3^{\circ}$, of equal luminance, and presented at the center of the screen. Both the screen and the monkey could be moved to different positions relative to each other (to investigate egocentric encoding) and relative to the room (to investigate absolute allocentric encoding). In an example of this protocol, the screen was moved to different locations in the room, and, for each screen location, the monkey was rotated so that recordings of neuronal activity were made when these different locations were on his right side, his left side, or centered in front of him. Using the magnetic eye coil method described by Judge et al. (1980), the abort limit for eye movements was set between $2^{\circ}-3^{\circ}$, to ensure that the monkey fixated upon the screen. In these tests only correct nonabort trials were used in the subsequent analyses.

Data analysis. For a given spatial manipulation, spikes were collected for several blocks of 17 or 20 trials, and they were stored on the computer for later analysis. Spikes were collected in 10- or 20 -msec bins, depending on the firing rate of the cell and the latency of the response. Spikes were recorded for the time period $200 \mathrm{msec}$ before the onset of the visual test stimulus (the onset was defined as Time 0 ) and for $800 \mathrm{msec}$ after the onset of the stimulus. The spike count for the period of time $200 \mathrm{msec}$ prior to the onset of the visual stimulus was used to calculate the spontaneous activity of the cell. At a later time, the response of the cell was analyzed statistically, by comparing the neuronal response to positions on the screen during the different spatial manipulations of the monkey and the screen (as is described below). The differential latency of the neuronal activity when stimuli were shown in different positions on the screen was determined by subtracting the peristimulus time histograms of neuronal activity for the different conditions, and calculating the cumulative sum statistic (Woodward \& Goldsmith, 1964) of this difference, using the firing in 18 prestimulus bins as the reference value. The point at which the slope of the cusum changed gave the latency.

The data from the different testing conditions were analyzed with both one-way and two-way analyses of variance (ANOVAs; Bruning \& Kintz, 1977; Sokal \& Rohlf, 1981). In the one-way ANOVAs, the data were arranged into the different categories according to the spatial hypothesis being tested. To test for frame-of-reference allocentric encoding, the data were arranged into four conditions, representing the four positions on the screen, irrespective of the location of the monkey or the screen. To test for egocentric encoding, the data were arranged into the positions relative to the monkey's body axis in which the stimuli had been shown during the original testing. For the absolute allocentric test, the data were ar- ranged according to the positions in the room in which each stimulus was shown during the original testing, irrespective of its egocentric or frame-of-reference position. By examining the $F$ values and the resultant $p$ values from the different one-way ANOVAs, one could identify which of the spatial hypotheses best fit the data, or in some cases eliminate at least one of the spatial hypotheses. The aim was to find which of these three ANOVAs produced maximum between-conditions and minimum within-conditions variance.

The results from the one-way ANOVAs were then confirmed by remainder (lack-of-fit) analyses, which indicated whether the remaining variance was sufficiently great to indicate that that hypothesis did not fit the data well, as is described in the Appendix. If a cell had a significant result in the one-way ANOVA according to that spatial hypothesis, and if the remainder was not significant, then that spatial hypothesis was accepted for that cell.

The two-way ANOVAs were calculated to give further information about the firing of the cells. To test for frame-of-reference encoding, the data were arranged so that the place on the screen (0-3) represented the four different conditions and the different positions of the screen and the monkey represented the groups. For example, if testing was performed with the screen centered in front of the monkey, and then to the left and then to the right of the monkey, these would represent three groups of data. If a cell showed a significant between-conditions effect, but no significant betweengroups effect or interaction, this was an indication that the cell was a frame-of-reference cell. Analogous analyses were performed for the absolute allocentric and egocentric hypotheses. It was of course only possible to classify a cell as absolute allocentric if both the monkey and the screen were moved and if, therefore, the egocentric hypothesis had been ruled out.

The results of the one-way ANOVAs, the remainder analyses, and the two-way ANOVAs were all used in evaluating the spatial coordinates in relation to which the cell responded. If a cell had both significant effects and remainders under more than one hypothesis, and there were interaction effects in the two-way ANOVAs, this indicated that no single spatial hypothesis tested accounted for the responses shown by the cell. Although .05 was taken as being statistically significant, most of the effects found here were significant at $p<.001$.

The cells that were tested with the earlier spatial tests, using the OP task, were also analyzed using similar ANOVAs. The data were sorted according to hypotheses of egocentric or allocentric coordinates, and the responses of the cells were analyzed with two oneway ANOVAs. (For these cells there was no test for frame of refer- 
ence.) For the two-way ANOVAs, the data were brought together such that egocentric (left, right, center) represented the different conditions and the absolute allocentric locations of the screen represented the groups factor. A strong between-conditions result indicated egocentric information processing, and a strong betweengroups result indicated allocentric information processing. For some cells, it was not possible to differentiate between the allocentric and egocentric hypotheses, but the results are included because they provide evidence that the cells were responding to some form of spatial information.

Recording techniques. The activity of single neurons was recorded with glass-insulated tungsten microelectrodes that were usually platinum plated (after Merrill \& Ainsworth, 1972) in 3 male macaque monkeys (Macaca mulatta) (weight 3.0-4.5 kg; age, 1-2 years) seated in a primate chair according to techniques that have been described previously (Rolls, Burton, \& Mora, 1976). The monkeys had been implanted under thiopentone sodium anesthesia with a stainless steel holder on which an adaptor that also supported the head could be fitted for the subsequent daily recording sessions. The action potentials of single cells were amplified according to techniques described previously (Rolls et al., 1979), converted into digital pulses with the trigger circuit of an oscilloscope, and analyzed on line, with a PDP-11 or Microvax II computer. We ensured that recordings were from only a single cell by continuously monitoring the interspike interval to make sure that intervals of less than $2 \mathrm{msec}$ were not seen, and by continuously monitoring the waveform of the recorded action potentials. The computer collected peristimulus rastergrams of neuronal activity for each trial, and displayed, printed, and stored each trial, as well as computed the peristimulus time histogram by summing trials of a given type.

$\mathrm{X}$-radiographs taken in the coronal and parasaggital planes were used to locate the position of the microelectrode on each recording track relative to permanently implanted reference electrodes and bony landmarks such as the posterior tip of the sphenoid bone (Aggleton \& Passingham, 1981). At the time of histology, the animals were narcotized with ketamine, deeply anesthetized with intravenous pentobarbitone sodium, and perfused with normal saline followed by $10 \%$ formal saline. Sharpened hollow tubes (diameter $=1.5 \mathrm{~mm}$ ) were passed stereotaxically through the brain parallel to the intra-aural/inferior orbital plane to provide a dorsoventral reference point between sections. The position of cells was reconstructed from the $\mathrm{X}$-ray coordinates taken together with serial $50-\mu$ histological sections in the coronal plane stained with Cresyl violet, which showed the reference electrodes and microlesions made at the end of some of the microelectrode tracks as follows. Drawings were made in coronal planes $0.5 \mathrm{~mm}$ apart from the $\mathrm{X}$ radiographs, showing the position of the electrode at the end of each track at a $10 \times$ scale. (The X-radiographs were corrected for the $10 \%$ magnification that occurred.) The position of each unit recorded was marked on these drawings. Toward the end of each experiment (in the last 2-3 weeks), small electrolytic lesions (40-80 $\mu \mathrm{A}$ for $50-60 \mathrm{sec}$ ) were made at the end of each recording session, usually at the site of a responsive neuron. $\mathrm{X}$-rays were again taken. This allowed the relationship between positions as measured on radiographs, and position in the brain when the microlesions were identified histologically, to be calculated. A linear regression was then performed in each of the three dimensions between measurements in the brain and measurements on the radiographs. The accuracy of reconstruction according to this method was better than $0.5 \mathrm{~mm}$.

\section{Results}

Of the 1,485 cells analyzed in 3 monkeys, 182 (12\%) had different responses to different positions in space in the MPOP, MPL, and TCH tasks. It was possible to investigate for $\mathbf{4 8}$ of these cells the spatial coordinate sys- tem in relation to which they responded by moving the screen and/or the monkey. (For the remaining cells, it was not possible to complete all the spatial tests while the cell was held.) Examples of the responses of the cells, and how the responses were analyzed, will be given first, and then a summary of the responses of all the cells analyzed will be given. The mean spontaneous firing rate of the spatial cells that responded by increasing their firing was $12.1 \pm 7.5(M \pm S D)$ spikes/s, and their responses increased to a mean of $28.7 \pm 8.1$. The mean spontaneous firing rate of the spatial cells that responded by decreasing their firing was $19.8 \pm 11.0$ spikes/s, and their responses decreased to a mean of $14.1 \pm 8.4$ spikes/s. For cells that increased their firing during the tasks, the mean latency was $184 \pm 75 \mathrm{msec}$, and for cells that decreased their firing during the tasks, the mean latency was $182 \pm 69 \mathrm{msec}$.

The responses of a cell that responded primarily in egocentric coordinates are shown in Figure 3. The cell was first tested with the screen in one fixed position (SC, screen central); and one set of neuronal responses to stimuli in different positions on the screen was obtained with the monkey placed centrally (MC) in front of the screen, a second set when the monkey was moved up (MU), and a third set when the monkey was moved down (MD), as is shown at the bottom of Figure 3. The firing rates when the stimuli were in the four different quadrants on the screen with the monkey in these different positions are shown sorted according to the position of the stimuli relative to the monkey-that is, in egocentric coordinates-on the right of Figure 3. It is clear that the higher the stimulus was, relative to the monkey, the greater was the firing rate of the neuron (right panel of Figure 3). Moreover, it is clear from the right panel of Figure 3 that the firing rate did not depend on where the stimulus had been on the screen originally-that is, on frame-of-reference coordinates. This is confirmed in the left panel of Figure 3, which shows the same data plotted in frame-of-reference coordinates. There was little consistent difference between different positions on the screen in frame-of-reference coordinates; rather, there was great variation in the response to each position on the screen, depending on whether the monkey was above, at the same level as, or below the screen. These findings were confirmed by the statistical analysis; a one-way ANOVA showed a highly significant effect of stimulus position in egocentric coordinates $(p=.003)$, but a nonsignificant effect in frame-of-reference coordinates $(p>.05)$ (because of the low between-conditions and high withinconditions variance). The cell did not respond in absolute allocentric coordinates (i.e., to position in the room) either, as is shown in the left panel of Figure 3, where the different positions in frame-of-reference space also represent the different positions in absolute allocentric space. These findings suggest that the hippocampal cell responded to different positions in egocentric space, but not in frame-of-reference or absolute allocentric space. (This was confirmed by the two-way ANOVAs. When 
Plotted in Absolute Allocentric and Frame of Reference Coordinates
Plottcd in Egocentric

Coordinates

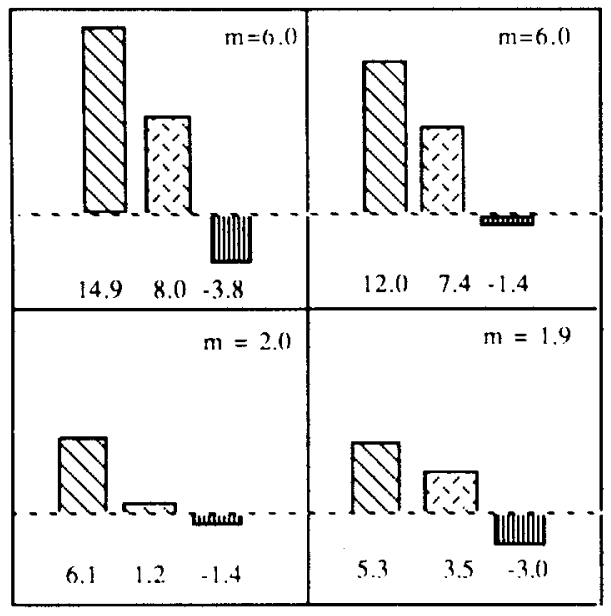

$F=2.3$
$d f=3,54$
$p=0.086$

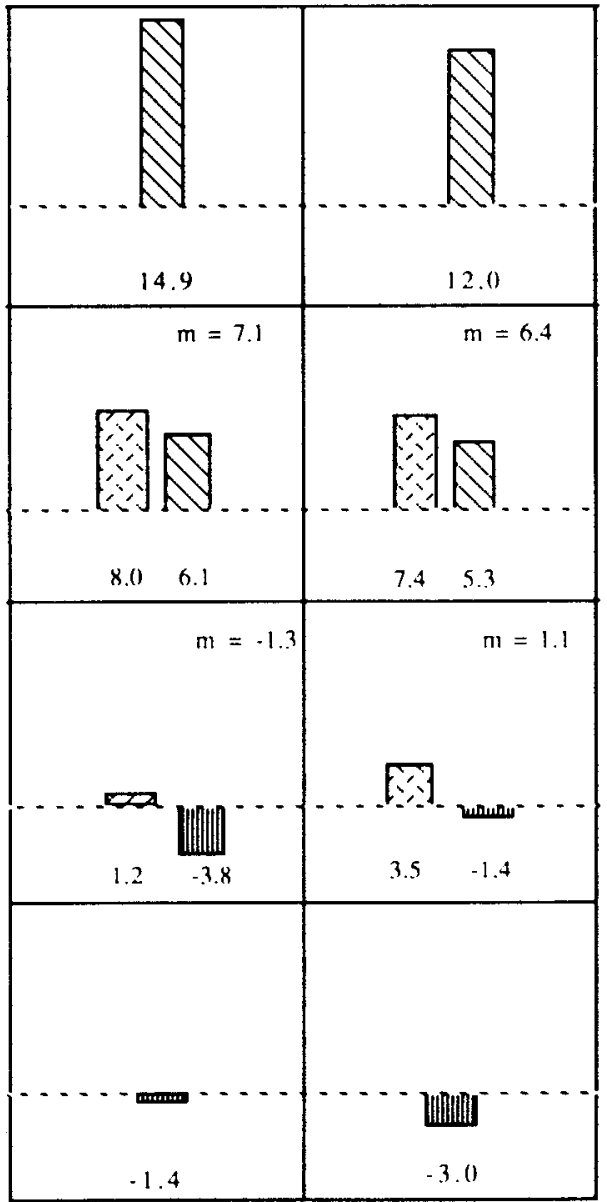

$\mathrm{F}=3.92$

$\mathrm{d} \mathrm{C}=7.50$

$\mathrm{p}=0.0031$

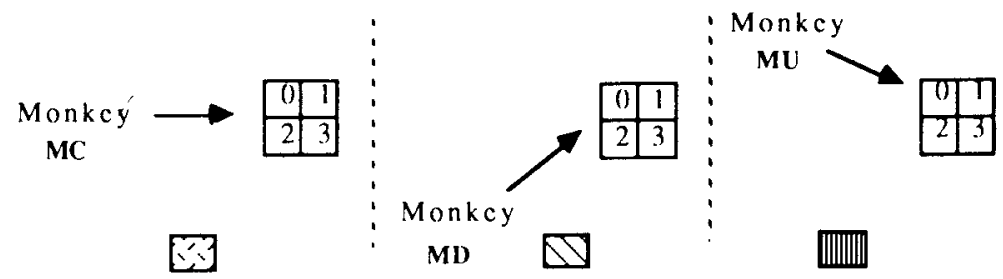

Figure 3. The responses of a hippocampal neuron that responded primarily in egocentric coordinates. The three spatial arrangements of the monkey and the screen in which the data were collected are shown at the bottom of the diagram. (The screen remained in the central position throughout, and data were collected with the monkey in the central position, MC; with the monkey moved down, MD; and with the monkey moved up, MU.) The right part of the diagram shows the firing rate of the neuron sorted according to the position of the stimuli relative to the monkey - that is, in egocentric coordinates. The center of the diagram was level with the eyes. The screen subtended $38^{\circ}$ at the retina, so that each small square in the diagram, in which each stimulus was shown, was $19^{\circ} \times 19^{\circ}$. The response of the cell is shown as the change in firing rate in spikes/s from the spontaneous rate by the bar histograms and the value shown below each histogram. Where data from more than one spatial arrangement of the screen and monkey are available, the mean response $(m=)$ is shown. The spatial test condition under which the data were obtained is shown by the hatching, and is referred to in the diagram below. The result of the one-way analysis of variance is shown. The diagram on the upper left shows the data plotted in frame-of-reference coordinates, which in this case were not separated from absolute allocentric coordinates, since the screen was not moved. 
the data were sorted so that the different conditions were places relative to the monkey-i.e., egocentric positionsand the different groups were the different positions of the monkey, there was a significant effect of condition $[p<.024]$, but not of group.)

The responses of a cell that responded primarily in absolute allocentric coordinates are shown in Figure 4. As is indicated in the inset, the cell was first tested with the monkey in the central position and the screen in the central position (MC SC). In order to analyze the neuronal responses obtained, more data were collected from the cell with the screen moved up (MC SU). Finally, the monkey and the screen were moved to a new position in the room and placed in the normal (MC SC) position with respect to each other (Figure 4). As a result of these manipulations, data were available for 10 different positions in absolute coordinates in the room, as is shown to the right in Figure 4A. The one-way ANOVA showed a highly significant effect of position in absolute allocentric space $(p<.001)$. Moreover, the remainder analysis suggested that the absolute allocentric hypothesis accounted for the data. In contrast, if the data were sorted according to the positions of the stimuli in egocentric (Figure 4B) or frame-of-reference allocentric (Figure $4 \mathrm{C}$ ) coordinates, the one-way ANOVA showed some significance, but there were significant remainders from these analyses, so that neither the egocentric nor the frame-of-reference hypothesis fully accounted for the data. (The two-way ANOVAs supported this result; the absolute allocentric betweenconditions effect was significant at $p<.001$, and the twoway ANOVAs testing for frame-of-reference and egocentric coordinates were not significant, $p>$.05.) These analyses thus show that this hippocampal cell responded to different positions in absolute allocentric but not frameof-reference or egocentric space.

The responses of a cell that responded in frame-ofreference coordinates are shown in Figure 5. As is indicated in the inset, the cell was tested first with the monkey in the central position and the screen in the central position (MC SC). Further data were collected from the cell with the screen moved left (MC SL) and then with the screen moved to the right (MC SR). When the data were sorted by the position of the stimuli on the screen (i.e., in frame-of-reference allocentric coordinates), it was found that the cell responded most to the upper right position on the screen, with some response to the lower right position on the screen (see Figure 5, top panel). Given the considerable consistency of the data when sorted according to frame-of-reference coordinates, the one-way ANOVA showed a highly significant effect of position in frame-of-reference allocentric space $(p=.00002)$. Moreover, if the data were sorted according to the positions of the stimuli in egocentric and absolute allocentric coordinates (Figure 5, bottom panel) (which were not distinguished in the testing for this cell), then no consistent firing for position was found, and the ANOVA was not significant $(p>.05)$. (The two-way ANOVAs supported this result: The ANOVA that tested for frame-of-reference allocentric between-condition effects was significant at $p=3 \times 10^{-6}$, and the ANOVA for egocentric/absolute allocentric effects showed no significant effect, $p>.05$.) These findings thus show that this hippocampal cell responded to different positions in frame-of-reference coordinates but not in absolute allocentric or egocentric coordinates.

As is confirmed by the various statistical tests performed on the data, the responses of the population of 48 spatial neurons analyzed are as follows. One cell responded only in absolute allocentric coordinates. Twenty-one neurons responded in frame-of-reference allocentric coordinates. Five neurons responded in egocentric coordinates. Twentyone neurons responded in relation to a combination of two or more of the spatial coordinates analyzed. (Of these 21 , 11 had significant remainders for all three hypotheses, showing that these neurons may have been influenced by the absolute location of the stimulus in the room as well as by egocentric and frame-of-reference position.) For 6 cells, it was possible to exclude frame-of-reference encoding, so these cells must have responded in relation to absolute allocentric or egocentric coordinates. For 4 cells, it was possible to exclude absolute allocentric encoding, so these cells must have responded in relation to frameof-reference or egocentric coordinates.

Overall, these analyses show that many hippocampal cells with spatial responses have activity that reflects frame-of-reference allocentric spatial coordinates, while relatively few in this sample and with these testing methods respond to the absolute position at which stimuli were shown in the testing room or in relation to egocentric coordinates. Some hippocampal neurons responded in relation to combinations of these different coordinate systems, though this may reflect incomplete testing of the cellular response.

Eight cells were tested with the monkey performing the visual discrimination (OP) task with the small screen placed in different positions relative to the monkey and in the room. Four of these cells had spatial responses in these types of testing - that is, the neuron responded to the visual stimulus, depending on the spatial position of the screen relative to the monkey or in the room. Two cells responded to absolute allocentric space and one cell to egocentric space. For the remaining cell, it is possible to state that it was responding to some form of space, but it was not possible to differentiate between egocentric and allocentric space, since an insufficient set of the manipulations of the screen and monkey were performed.

\section{EXPERIMENT 2}

If a hippocampal neuron responded differently to stimuli in different positions on the screen in the spatial tasks such as MPOP and MPL, two hypotheses about the bases of the spatial response that were investigated are the following. First, the spatial response of the neuron might be determined in retinotopic coordinates. For example, a neuron that responded to the top left of the screen might have 

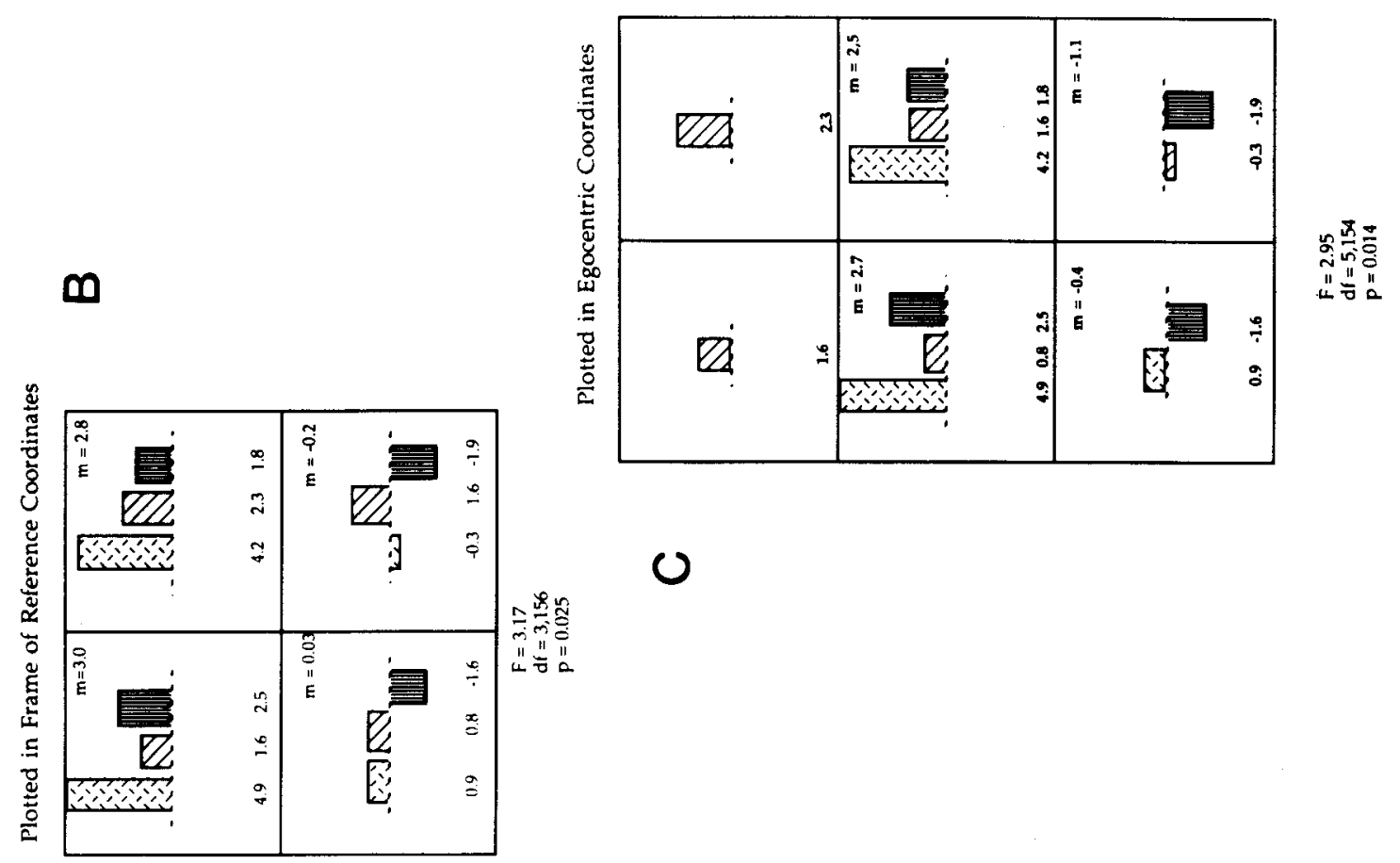

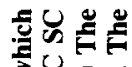

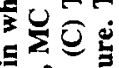

牙密 政

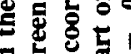

鸟

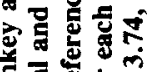
政

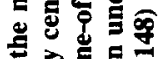
혈

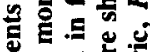

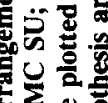

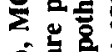
동

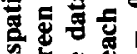

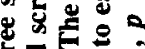

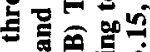



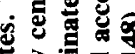

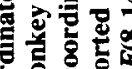
용 证高 空

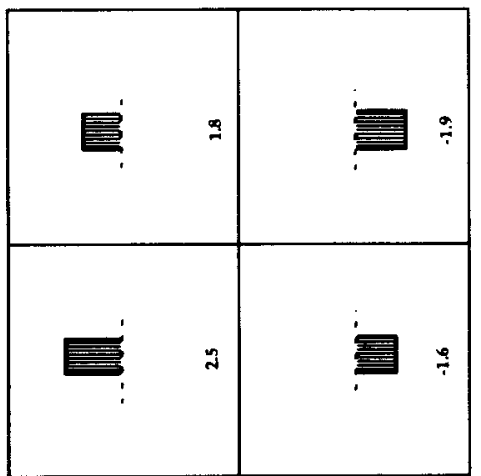

$\underbrace{\infty}_{\Sigma}$
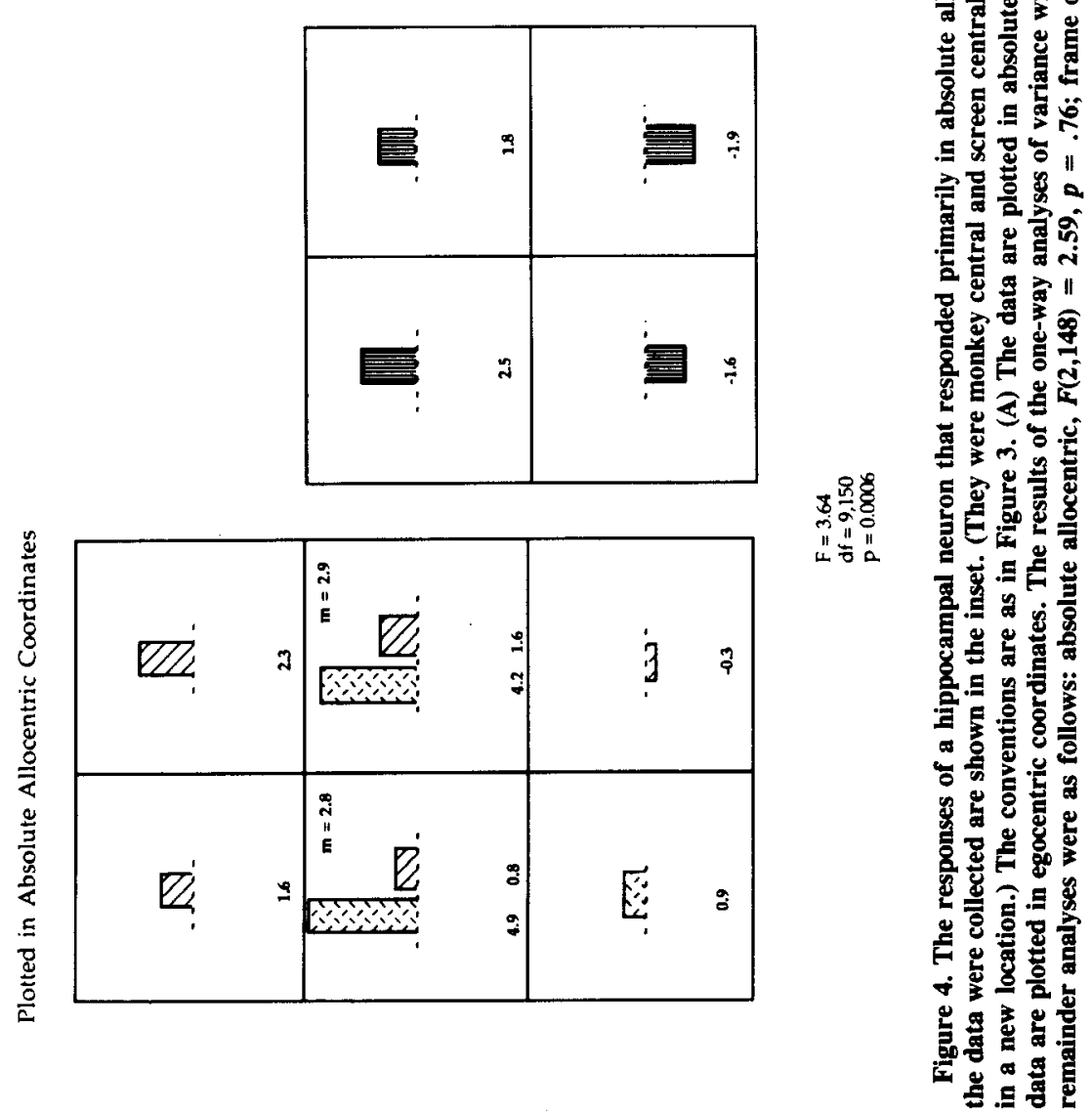
Plotted in Frame of Reference Coordinates

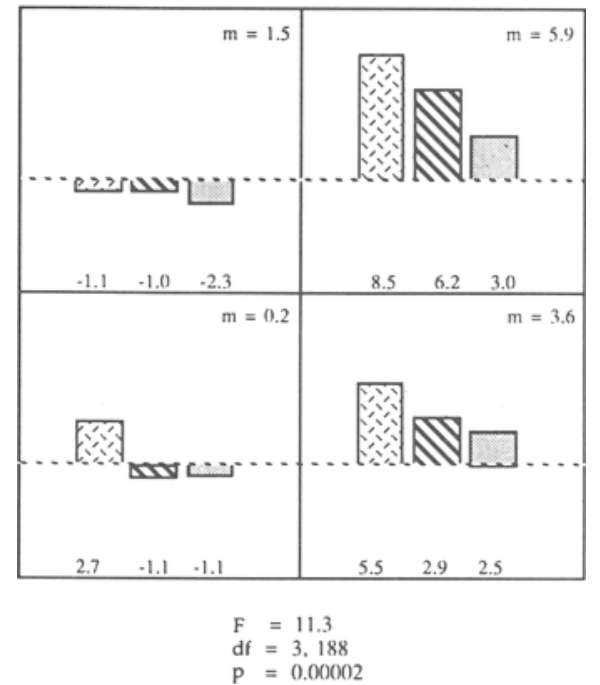

Plotted in Absolute Allocentric/Egocentric Coordinates
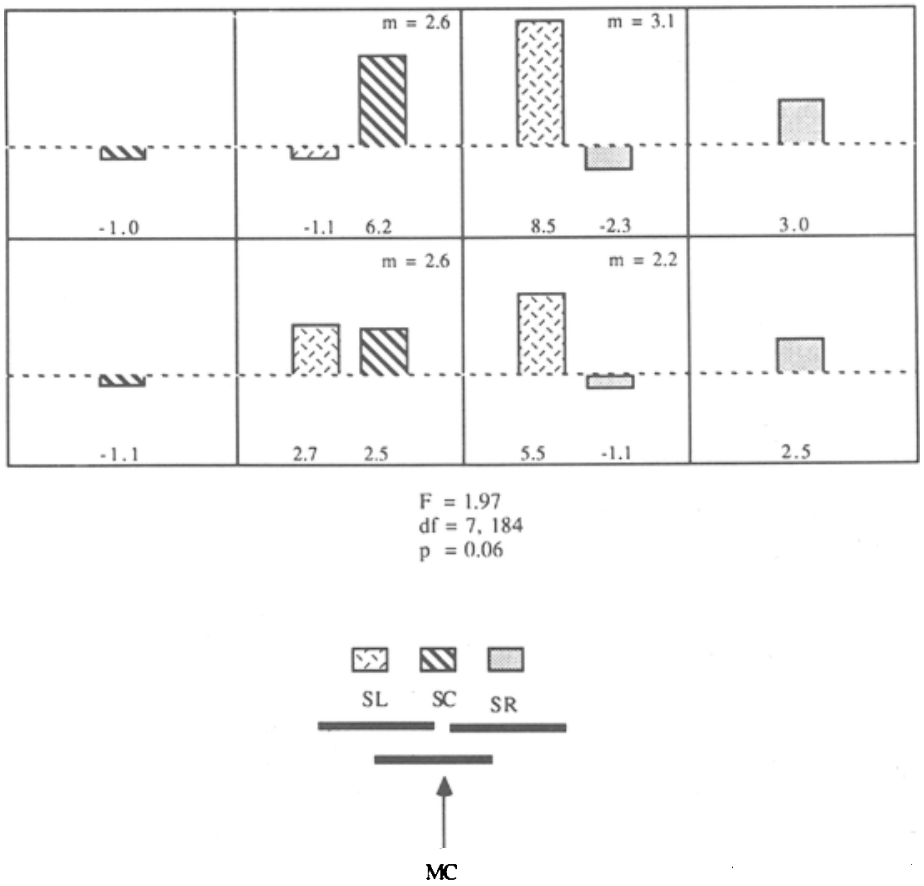

Figure 5. The responses of a hippocampal neuron that responded primarily in frame-of-reference allocentric coordinates. The three spatial arrangements of the monkey and the screen in which the data were collected are shown at the bottom of the figure. (They were monkey central and screen central, MC SC; monkey central and screen left, MC SL; monkey central and screen right, MC SR). The conventions are as in Figure 3. Top: The data are plotted in frame-of-reference coordinates. Bottom: The data are plotted in egocentric coordinates, which in this case were not separated from absolute allocentric coordinates, because the monkey was not moved. 
a field in the upper left half of visual space in retinotopic coordinates, which would be stimulated if the monkey tended to fixate toward the center of the screen. Second, the spatial response of a neuron might be determined in head-based coordinates-that is, it might respond to a given position in space relative to the head, and be relatively independent of eye position and of the part of the retina stimulated (but would respond to the appropriate combinations of these two). One of these hypotheses might hold for neurons shown in Experiment 1 that responded at least partly in egocentric coordinates; frame-ofreference allocentric and absolute allocentric cells should respond relatively independently or inconsistently with respect to space defined in both retinotopic and headcentered coordinates, and this is therefore the predicted response for the majority of neurons of the type recorded in Experiment 1. To investigate whether spatial neurons responded in retinotopic coordinates, in Experiment 2 the monkey performed a "spot task," in which he was required to fixate one position on the screen while large test spots of light were switched on during a trial at different positions relative to the fovea. In subsequent blocks of trials, the monkey was required to fixate a different position on the screen (that is, a new gaze angle was used), and the test spots were repeated in the same positions relative to the fovea. If a neuron responded in retinotopic coordinates, the neuronal response should be independent of the gaze angle, and dependent only on the position of the spot relative to the fovea. On the other hand, if the neuron responded in head coordinates, then the neuron should respond only to some positions on the screen, independently of the particular combination of gaze angle and retinal coordinate. Another possibility is that the neuron might respond preferentially to particular combinations of eye gaze and retinal angle, thus providing some information which could be interpreted in head angle coordinates (cf. Andersen, 1987). In this experiment, neurons that fire to frame-of-reference or absolute allocentric coordinates should respond relatively independently or inconsistently with respect to space defined in both retinotopic and head-centered coordinates, because the latter coordinate systems reflect different types of, egocentric, encoding.

\section{Method}

In this task, the monkey sat with his head facing a tangent screen $100 \mathrm{~cm}$ away, which subtended $38^{\circ}$ at the retina. The central line of gaze was set at the center of the screen and defined as $0^{\circ}$ horizontal and vertical. Eye position was measured to an accuracy of $0.2^{\circ}$ using the search coil method (Judge et al., 1980).

In one block of trials in the spot task, a fixation spot (which subtended $1.9^{\circ}$ at the retina) appeared on each trial at Time $-500 \mathrm{msec}$ in a given position on the screen. A 500-msec tone started at the same time to indicate the start of a trial. The monkey had $500 \mathrm{msec}$ to fixate the spot, and was required to maintain fixation from Time 0 until the fixation spot dimmed at a randomly determined time in the interval 500-2,500 msec. When the fixation spot dimmed, there was a 1 -sec period within which the monkey could lick a tube in front of his mouth to obtain fruit juice. Licking before the fixation spot dimmed resulted in the delivery of saline. The fixation spot was adjusted to dim by such a small amount that the monkey could only detect its dimming by fixating it. In addition, if the eyes moved from the fixation spot more than $1^{\circ}$ before it dimmed, the computer aborted the trial, and the next trial was delayed. At Time 0 , the test spot was turned on in one of five positions relative to the fixation spot (see Figure 6, top panel). The test spot had a diameter of $6.6^{\circ}$ and a brightness of $4 \mathrm{fL}$. The task was run with the fixation spot in the central position on the screen for 20-40 trials. The firing rate of the neuron was measured in the period 100-600 $\mathrm{msec}$ after the test spot was turned on.

If a cell was found with a differential response to one of the test spot locations in this spot task, the central fixation spot could then be moved to a new location on the screen. When the fixation spot was moved, all other parameters remained the same; in particular, the test spots maintained their original positions relative to the fixation spot (see Figure 6, bottom panel). Only correct nonabort trials were used in the statistical analyses of the neuronal responses. The monkey typically performed the task with $95 \%$ correct trials.

The activity of each neuron measured in the $100-$ to $600-\mathrm{msec}$ period after the onset of the test spot was compared for each of the five possible test spot positions. ANOVAs were performed with the data sorted according to retinotopic position of the test spot or position of the test spot on the screen. An example of this analysis is provided below.

\section{Results}

The activity of 289 cells (a subpopulation of the cells recorded in Experiment 1) was recorded from the 3 mon-
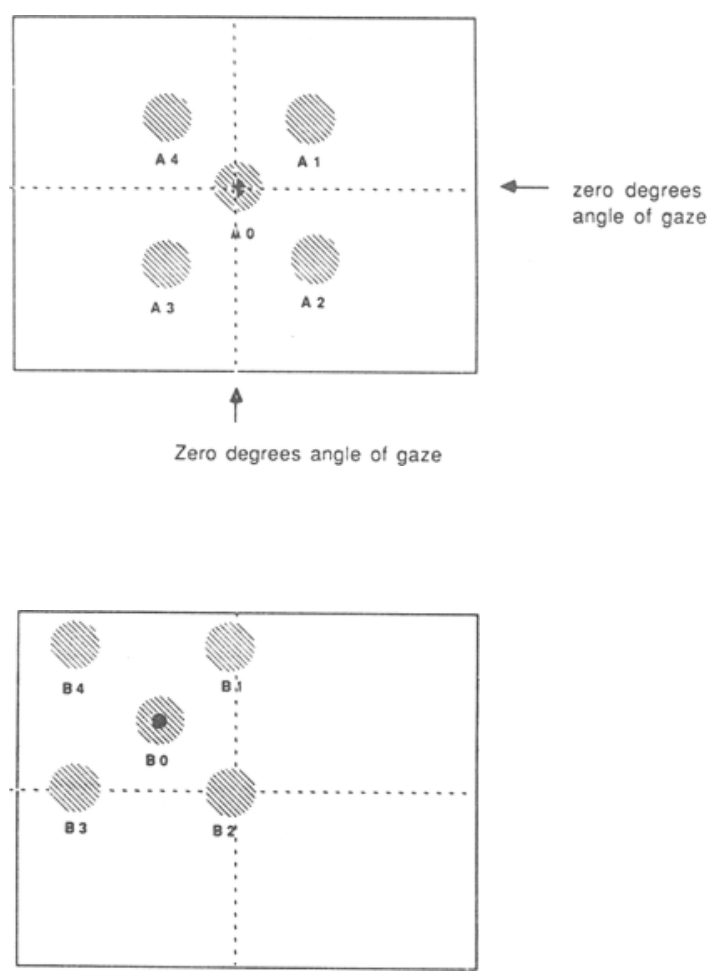

Figure 6. Spot task. Top: The monkey fixated a fixation spot in front of him level with the eyes, and during steady fixation, a test spot of light that subtended $6.6^{\circ}$ at the retina appeared in one of the five positions A0-A5 indicated. Bottom: To determine whether the gaze angle altered the neuronal response to the test spots, on separate blocks of trials the fixation spot was moved to a different position relative to the monkey's head, and the test spots were shown in the same retinotopic positions as before (e.g., B0-B4). The screen subtended $38^{\circ}$ at the retina. 
keys used in Experiment 1 during the spot task. An example of a cell (SSO48-193) with a spatial response in this task is shown in Figure 7. The rastergram, peristimulus time histogram, and eye position plots are shown. The fixation spot for the data shown in Figure 7 was at the center of the screen. The responses of the same cell when the central fixation spot was moved to different positions on the screen are shown in Figure 8 (top panel). The cell responded most when the stimuli were toward the lower right of the screen. The response was not consistent for any particular position relative to the fovea. This is con- firmed in Figure 8 (bottom panel), in which the responses are plotted relative to the fovea-that is, in retinotopic coordinates. For example, when the monkey was fixating toward the lower right of the screen, there was a large neuronal response for most locations of the test spot around this fixation point. In contrast, the further the stimulus was toward the lower right of the screen, in general the larger was its response (Figure 8, top). In Experiment 1 , this cell responded to frame-of-reference coordinates. The results of the one-way ANOVA for the spot task were consistent with this finding, in showing

\section{Pos. 4}
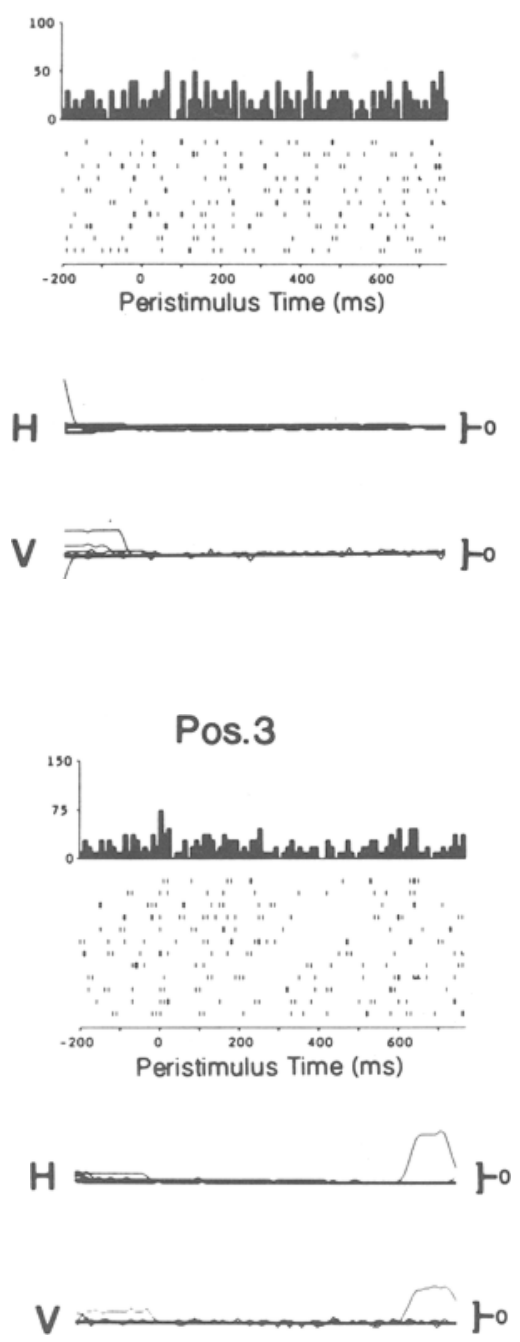
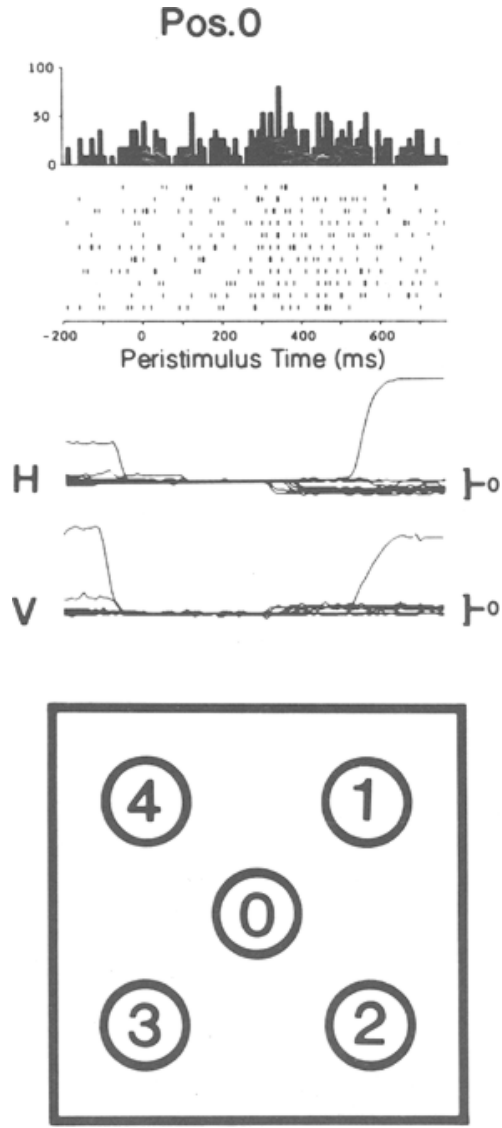

Pos.1


Pos.2

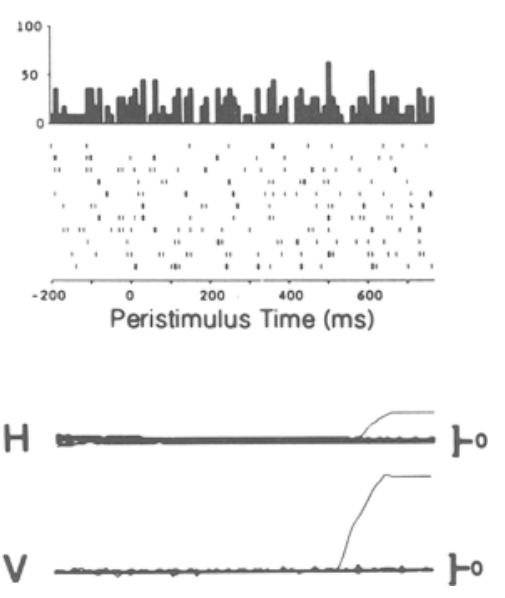

Figure 7. Peristimulus time histograms and rastergrams showing the responses of a hippocampal neuron in the spot task. The test spot appeared at Time 0 in one of the positions $0-4$. The central small fixation spot appeared at Time -500 msec, and fixation of it was maintained well for at least the period $0-500 \mathrm{msec}$, as is shown by the horizontal and vertical eye position recordings that accompany the data for each position. 


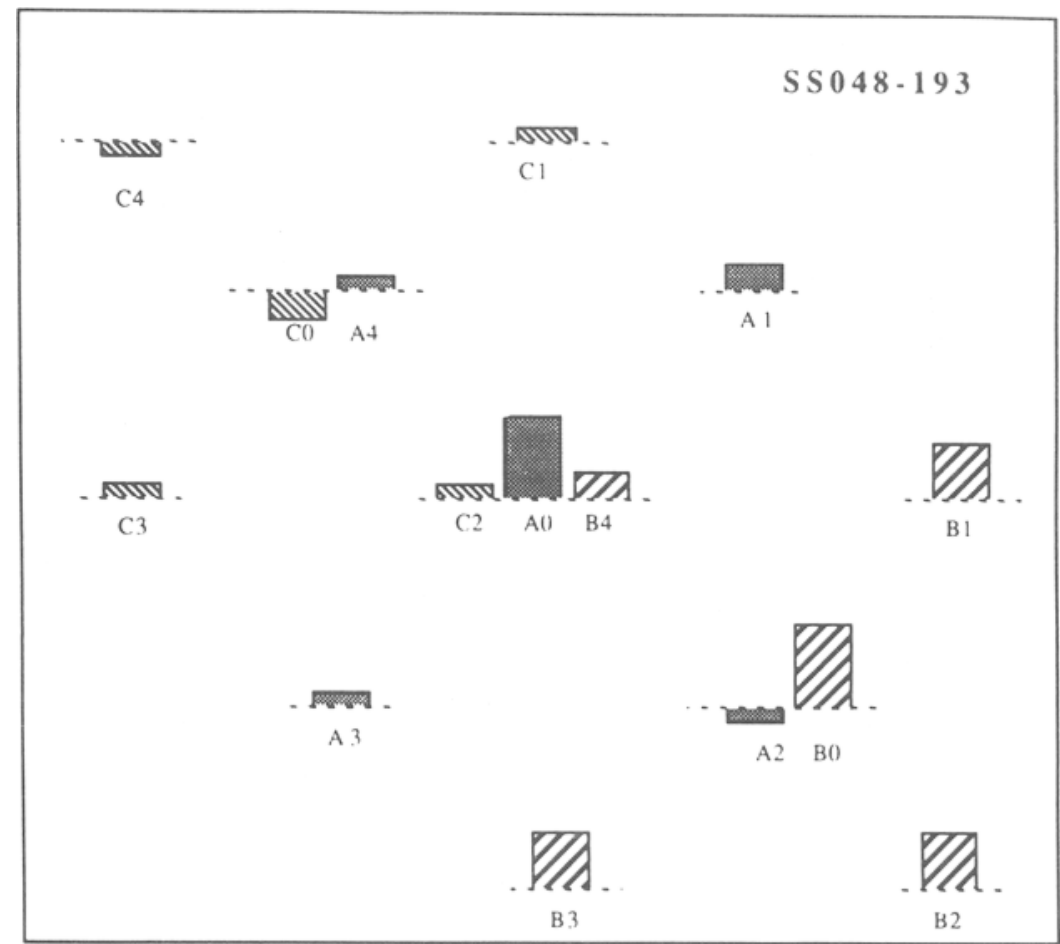

The dashed lines indicate spontaneous rate. $($ spont. $=8.1+2.3 \mathrm{sp} / \mathrm{s})$

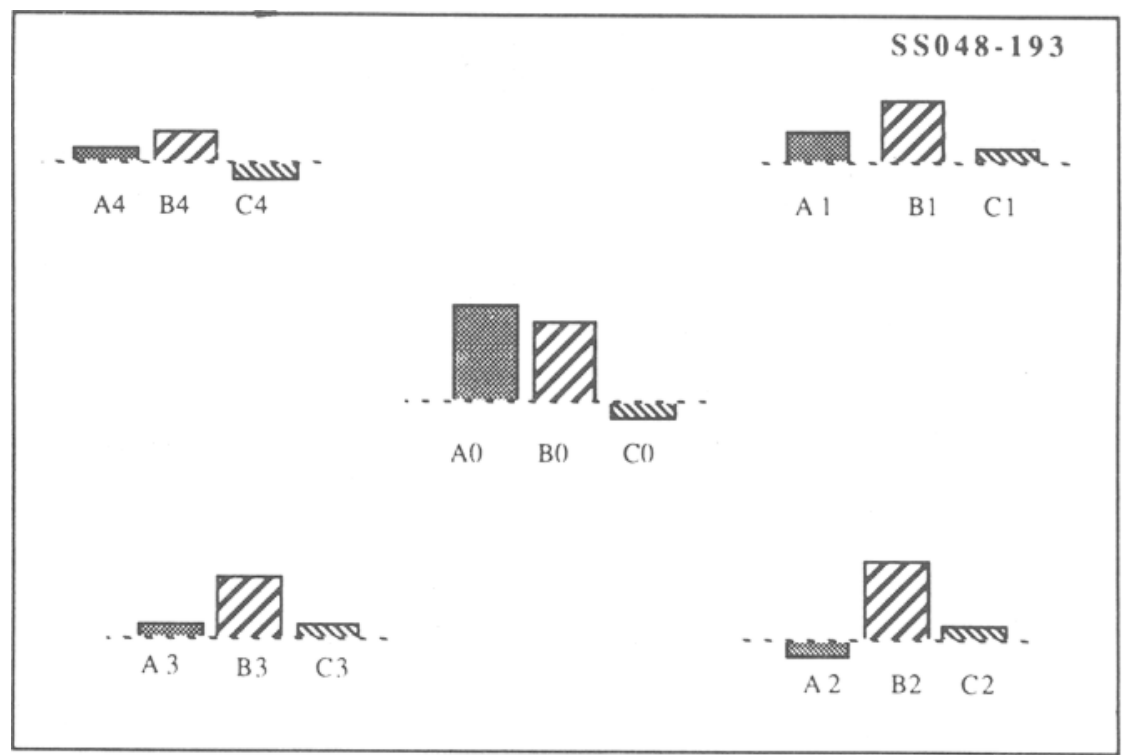

Dashed lines indicate spontaneous rate $(8.1+2.3 \mathrm{sp} / \mathrm{s})$

Figure 8. Top: Example of the responses, shown by the height of the histogram and the accompanying value in spikes/s, of a hippocampal neuron in the spot task. The neuron is the same as that shown in Figure 7. The fixation spot was placed at three different locations on the screen for different blocks of trials. Group A represents the data with the fixation spot at the center of the screen. Group B shows the data when the fixation spot was moved to coincide with the position of the test spot A2. Group C shows the data when the fixation spot was moved to coincide with the position of the test spot A4. The cell tended to respond more when the test spot was toward the lower right of the screen (and this was confirmed by a one-way ANOVA that showed this effect to be significant at the $p=.0003$ level). Bottom: The same data as those shown in the top panel, plotted according to retinotopic position (i.e., relative to the fovea). There was no consistent effect of retinotopic position (and this was confirmed by a one-way ANOVA, which showed no significant effect, $p=.13$ ). 
that the cell did not respond in relation to retinotopic coordinates. On the other hand, an ANOVA that tested for whether the neuron responded in relation to the position of the test spot on the screen (independently of the retinal location of the spot; that is, combining data across all eye gaze angles tested) showed a highly significant effect $(p<.0003)$.

Eleven neurons (3.8\% of the neurons tested) showed a statistically significant differential response to one or more of the test spot locations in the task. For 6 of these cells, the maximal response occurred when the test spot was shown at the fovea, and for 5 cells for one of the extrafoveal positions. Three of these 5 cells with extrafoveal fields were tested by moving the central fixation spot to a new location on the screen. None of these cells responded to the test spots in the same retinotopic position with the new gaze angle, so it was concluded that these cells did not encode in retinotopic coordinates. Instead, the cells could have encoded in head-based egocentric, or in frame-of-reference or absolute allocentric coordinates. These results were confirmed by both oneway and two-way ANOVAs. Of the 289 cells tested, 68 had spatial responses in the spatial tasks used in Experiment 1 , and 57 of these 68 did not respond in the spot task. Taken together, these results suggest that, in general, neurons in the hippocampal formation with spatial responses do not respond simply in relation to the position of a stimulus on the retina, and thus do not utilize retinotopic encoding.

\section{EXPERIMENT 3}

To determine whether showing a stimulus at the fovea while the monkey was looking at different positions in space might be an adequate stimulus for some hippocam- pal spatial neurons, the monkey was taught an eye position task. In this task, the monkey performed a visual fixation task in which the position of the fixation spot on the screen varied from trial to trial, thus allowing neuronal firing to be measured when eye gaze position, but not the retinotopic position, of the stimulus varied.

\section{Method}

In this task, the monkey sat with his head facing a tangent screen that subtended $38^{\circ}$ at the retina and was $100 \mathrm{~cm}$ away. The central line of gaze was set at the center of the screen and defined as $0^{\circ}$ horizontal and vertical. Eye position was measured to an accuracy of $0.2^{\circ}$ with the search coil method (Judge et al., 1980). In this eye position task (Figure 9), a small fixation spot (subtending $1.9^{\circ}$ at the retina, brightness $4 \mathrm{fL}$ ) appeared at Time $-500 \mathrm{msec}$ in one of nine locations (in random sequence) on the large video projection screen, which subtended $38^{\circ}$ at the retina. A $500-\mathrm{msec}$ signal tone started at the same time. The monkey had $500 \mathrm{msec}$ to fixate the fixation spot, and was required to maintain fixation from Time 0 until the fixation spot dimmed at a randomly determined time in the interval 500-2,500 msec. When the fixation spot dimmed, there was a $1-\mathrm{sec}$ period within which the monkey could lick a tube in front of his mouth to obtain fruit juice. Licking before the fixation spot dimmed resulted in the delivery of saline. The fixation spot was adjusted to dim by such a small amount that the monkey could only detect its dimming by fixating it. In addition, if the eyes moved from the fixation spot more than $1^{\circ}$ before it dimmed, the computer aborted the trial, and the next trial was delayed. The firing rate of the neuron was measured in the period 100-600 msec after the test spot was turned on-that is, for approximately the first $500 \mathrm{msec}$ of the neuronal response. Only correct nonabort trials were used in the statistical analyses of the neuronal responses. The monkey typically performed the task with $95 \%$ correct trials.

The activity for each neuron was compared for each of nine fixation spot positions in the eye position task. ANOVAs were run on all sets of data to determine whether there was a significant difference for any particular position of the fixation spots in the eye position task.
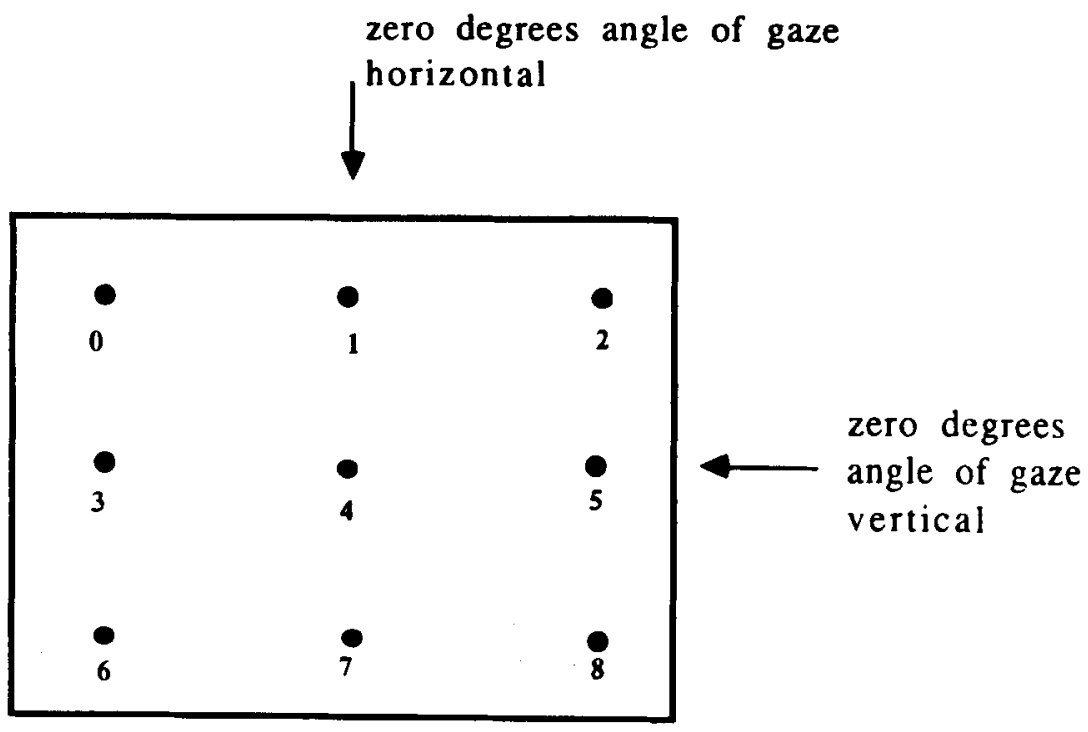

Figure 9. Eye position task. The fixation spot appeared at one of the nine positions shown on each trial, and the neuronal response was measured during steady fixation of the spot in each position in space. 

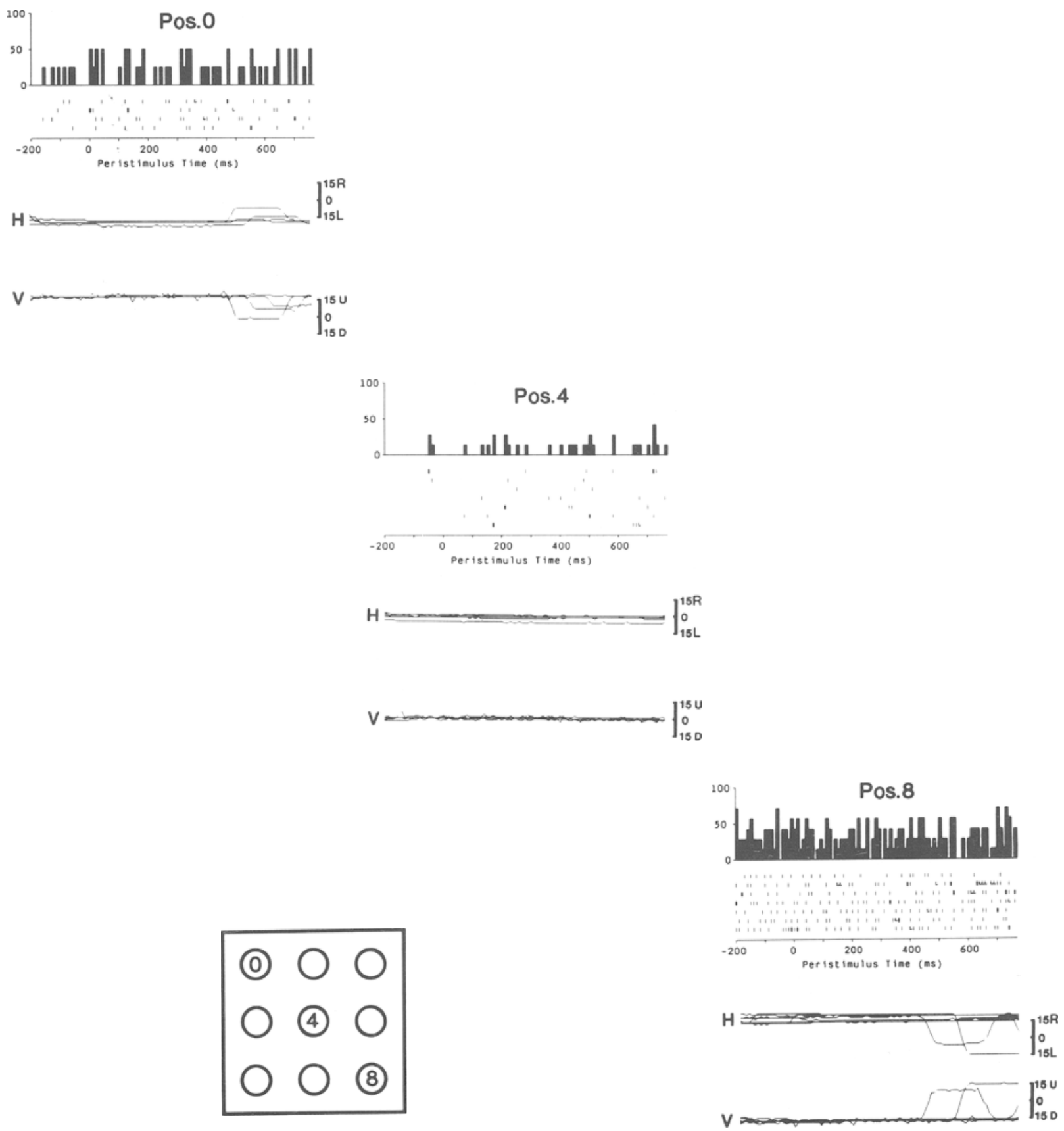

Figure 10. Peristimulus time histograms and rastergrams showing the responses of a hippocampal neuron in the eye position task. The small fixation spot appeared at Time $-\mathbf{5 0 0} \mathrm{msec}$, and fixation of it was maintained well for at least the period 0-500 msec, as is shown by the horizontal and vertical eye position recordings calibrated in degrees relative to the central position (4), which accompany the data for each position. 


\section{Results}

The activity of 47 neurons from 2 of the 3 monkeys used in Experiment 1 was tested using the eye position task. Eight cells (17\% of those tested) showed a statistically significant differential response when the fixation spot was shown at different positions on the screen. (Seven of these 8 also had spatial responses in the spatial tasks described in Experiment 1.)

The responses of a cell that had differential responses in the eye position task are illustrated in Figure 10. Rastergrams, peristimulus time histograms, and eye position plots for three of the positions on the screen (as indicated) are shown for the cell (SSO48-193). The neuron responded most when the fixation spot appeared toward the lower right of the screen.

Figure 11 shows the activity of Neuron SS048-193 in the fixation task. (This is the neuron whose activity in the spot task was illustrated in Figures 8 and 9.) The neuron responded most in the fixation task when the monkey was fixating the lower right and the right positions on the screen. This is further evidence that the responses of the majority of these hippocampal neurons do not have activity that occurs in retinotopic coordinates. Instead, the findings in this task show that the responses of these neu- rons often occur when stimuli are shown at a position in space being fixated. For the neurons shown in Experiment 1 to respond in relation to egocentric coordinates (one of which was tested in the eye position task), the results described here in the eye position task suggest that these egocentric responses arise not because of retinotopic encoding by these neurons, but instead because a stimulus at a position in space relative to the monkey's head is fixated.

The goodness-of-fit test for comparison to a normal distribution showed that the 8 cells with significant spatial responses of the 47 tested in the eye position task were more than would be expected by chance $[Z=8.1, p<$ $.001]$. This statistical analysis therefore confirms that there is a population of cells in the hippocampal formation that responds when the monkey is fixating stimuli in some positions but not in other positions in space. Moreover, the findings in the eye position task show that the spatial responses are not generated in retinotopic coordinates.

\section{Anatomical Localization}

The sites in the brain of the spatial cells tested in these experiments are shown in Figure 12. As can be seen from the histological reconstructions, there is no apparent

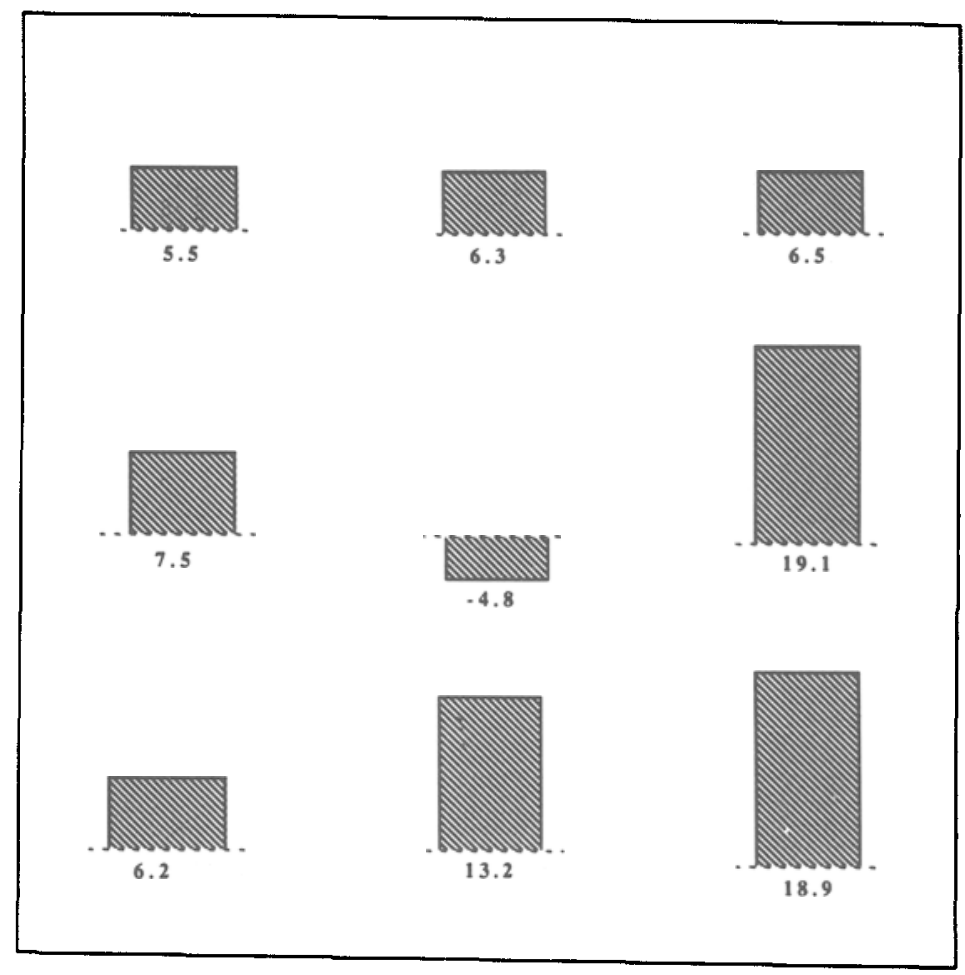

Figure 11. Example of the responses, shown by the height of the histogram and the accompanying value in spikes/s, of a hippocampal neuron in the eye position task. The neuron is the same as that shown in Figures 8, 9, and 10 . The cell responded more when the fixation spot was toward the lower right of the screen (and this was confirmed by a one-way ANOVA, which showed this effect to be significant at the $p<.001$ level). 


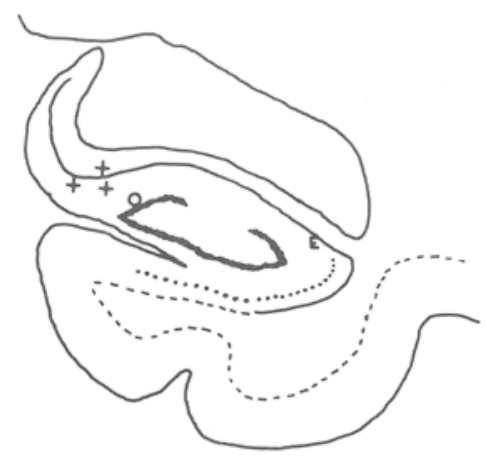

P6

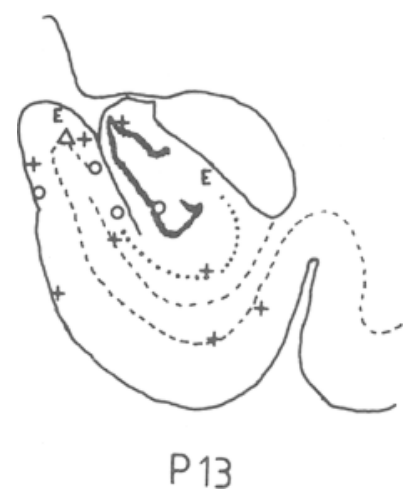

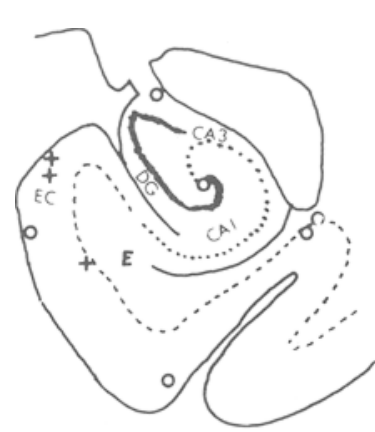

P9

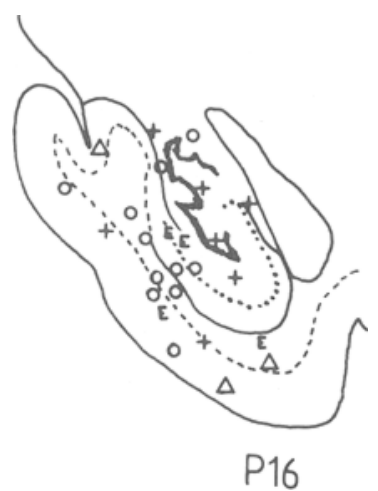

Figure 12. Examples of the anatomical positions of the different neurons recorded in this investigation. The neurons are shown on coronal sections taken at the different distances shown in millimeters posterior $(P)$ to the sphenoid reference. $+=$ frame-of-reference cells; $\mathbf{E}=$ egocentric cells; $\Delta=$ absolute allocentric cells; $O=$ cells that responded in relation to more than one coordinate system. CA1 and $\mathrm{CA}^{3}$ = subfields of Ammon's horn of the hippocampus; $\mathrm{DG}=$ dentate gyrus; $\mathbf{E C}=$ entorhinal cortex.

clustering of cells with the types of spatial response described here. The spatially responsive cells were found in many areas of the hippocampal formation (including CA3, CA1, dentate gyrus, entorhinal cortex, subiculum, and parahippocampal gyrus areas TF-TH) from which the population was recorded, and at all levels in the anterior/posterior dimension. The neuronal activity recorded from the hippocampus proper could not easily be classified in terms of the "theta" versus "complex spike" types found in subprimate species such as the rat and rabbit, and is discussed in more detail elsewhere (Rolls et al., 1989).

\section{DISCUSSION}

The results described here confirm the findings of Rolls et al. (1989) and Cahusac, Miyashita, and Rolls (1989) that there are neurons in the primate hippocampus that respond to spatial information, as is seen from differential firing that depends on where a stimulus is shown in space. The primary aim in the experiments described here was to provide evidence about the representation of space that is present in the hippocampal formation. It was found that many hippocampal cells with spatial responses have activity that reflects allocentric frame-of-reference spatial coordinates. In particular, of the 36 neurons in which frame-of-reference encoding could be separated from egocentric and absolute allocentric, 21 were found to respond primarily in frame-of-reference coordinates, and another 6 responded more in relation to the frame-of-reference than to the other hypotheses. Thus, $56 \%$ of the neurons analyzed responded more in relation to space defined by the local frame of reference than in relation to space defined by egocentric or in absolute allocentric coordinates. In contrast, of the 26 neurons in which egocentric coordinates could be separated from other types of spatial representation, only 5 responded primarily in relation to egocentric coordinates. Although absolute allocentric coordinates were only investigated for 11 neurons, for 5 of these cells, evidence was obtained that the neuronal response depended on the absolute allocentric position at which stimuli were shown in the testing room. Further evidence for the importance of absolute allocentric encoding was obtained in the task in which the smaller mon- 
itor screen was moved to different positions in the room, and 2 out of 4 cells recorded with this simpler task responded according to the absolute allocentric hypothesis.

The small number of spatial cells $(42 / 1,485)$ found in the population of cells recorded may reflect a number of properties of encoding of information by cell populations in the hippocampus. First, the spatial cells found were recorded in one room, and it is likely that other spatial environments can also be encoded by the hippocampus. Second, for a large number of memories to be encoded and stored in a population of neurons, it is for most types of neuron and for most learning rules advantageous to use sparse encoding (in which only few cells respond to any one stimulus) (Rolls, 1987; Treves \& Rolls, 1990; Treves, 1990). Third, some hippocampal cells in primates respond in relation to other classes of input than the spatial position of stimuli. These other classes include neurons that respond in (nonspatial) recognition memory tasks (Rolls, Cahusac, Feigenbaum, \& Miyashita, in press; see also, for the rat, Olton, Wible, Pang, \& Sakurai, 1989), in tasks in which spatial behavioral responses must be made to nonspatial stimuli (Cahusac et al., 1989; Miyashita, Rolls, Cahusac, Niki, \& Feigenbaum, 1989), and to whether a stimulus has been seen in a particular position in space previously (Rolls et al., 1989).

The different tasks described in this paper require the monkey to learn and remember several different properties of the stimuli, such as their spatial location, their identity, and the recency with which they have been seen. The hippocampal cells found may reflect the fact that the monkey is performing these spatial and memory tasks. For example, frame-of-reference allocentric coordinates are useful in solving the MPL task, and in the present study, evidence that some hippocampal cells respond in relation to frame-of-reference coordinates was found.

The finding that many hippocampal spatial neurons fire in local, frame-of-reference coordinates is of interest, for it suggests that quite local spatial relations between a small number of features may be represented in the brain by the firing of single neurons, and moreover that the brain may build more global representations of space from such neurons. If even pairwise spatial relations between (pairs of) features could be represented in this way, then more complex objects of representations of space could be formed by associating together a number of these lower order neurons. Indeed, it has been suggested that the microcircuitry and synaptic learning rules of the hippocampus are appropriate for performing this association (Rolls, 1989a, 1989b, 1990), which is implemented in particular by the CA3 neurons that form an autoassociation matrix memory. The autoassociation arises because of the well-developed recurrent collateral projections of the CA3 neurons, which allow any $\mathrm{CA} 3$ neuron to have a relatively high probability $-4 \%$ in the rat-of contacting any other CA3 neuron, and because the synapses made between CA3 neurons are Hebb-modifiable, as has been shown in studies of long-term potentiation (see Miles, 1988; Rolls, 1989a, 1989b). It has been suggested (Rolls, 1989b, 1990) that this autoassociation enables "whole scene" spatial memories (Gaffan \& Harrison, 1989b) to be built by associating together a set of conjunctive spatial cues. For example, a particular place might be defined by the association together of a set of spatial cues such as one feature in one location, a second feature in a second location, and so forth, for several features. Indeed, the hippocampal neurons described here that respond in relation to roombased coordinates ("absolute allocentric') could be formed in this way. The autoassociation also accounts for the importance of the hippocampus in episodic memories, which consist of an associated set of events. In addition, the hypothesis accounts for the difficulty humans and monkeys with hippocampal damage have in object-place memory tasks. In all these tasks, the key feature that is suggested with regard to the hippocampus is that it enables arbitrary sets of its inputs derived from widely different parts of the cerebral association cortex to be associated together (Rolls, 1989b, 1990).

Much of the spatial information used by the hippocampus in forming these spatial memories is likely to be derived from the parietal cortex, which provides major inputs to the hippocampus via the parahippocampal gyrus and entorhinal cortex (Van Hoesen, 1982). It will be of interest in future studies to determine whether within the parietal cortex local spatial relations between stimuli are encoded in neuronal activity, as seems to be the case for the frameof-reference neurons described here in the hippocampus, or whether such representations are developed more particularly in the parahippocampal gyrus or hippocampal formation. In view of the back projections from the hippocampus via the parahippocampal gyrus to the parietal cortex, which may guide memory storage in the parietal cortex (Rolls, 1989a, 1989b), such allocentric representations might be expected in the parietal cortex. The relative paucity of egocentric cells found in the primate hippocampus in this study may mean that the hippocampus is less concerned with directing movements in extrapersonal space (i.e., relative to the body axis) than is the parietal cortex, but, on the other hand, that it is more concerned with associations involving learning about objects and their relations in a body-axis invariant way-that is, in allocentric coordinates. Indeed, forming memories of where objects are in relation to the body axis is not generally useful except in short-term memory, and storing the locations of objects in real-world, allocentric, coordinates is what is required for the longer term memories for the formation of which the hippocampus is required.

One possible factor in the spatial responses of hippocampal cells is differential sensitivity to visual stimuli at different positions relative to the fovea-that is, sensitivity in retinotopic coordinates. This was investigated in the spot task, in which $6.6^{\circ}$ spots of light were presented at different retinotopic positions while the monkey main- 
tained fixation of a constant fixation point. Relatively few cells $(11 / 289$ or $3.8 \%$ of those tested) had spatial fields in the spot task, and of these 11 cells, only 5 had maximal responses for extrafoveal spots. This finding suggests that sensitivity to visual stimuli at particular positions relative to the fovea was not a major factor in the spatial responsiveness of hippocampal neurons, although experiments with a wider range of test stimuli than spots might produce a larger yield of responsive neurons in this type of task. The finding that the spatial field of one of the three neurons tested in this task with different fixation points did maintain its position relative to the fixation point suggests that retinotopic sensitivity could be a factor for a few hippocampal spatial neurons, and might therefore be investigated further.

Another possible factor in the spatial responses of hippocampal neurons is that the spatial responses might occur when stimuli at different positions in space are viewed. In this case, there would be no retinotopic cue. To test for this possibility, the eye position task was run (Experiment 3 ). In this task, the firing rate of the neuron was measured while a small spot was fixated in different positions on the monitor screen. It was found that this was an effective task for activating hippocampal spatial neurons, with $17 \%$ of the cells tested showing differential responses. These findings thus show that the visual stimulus need not be eccentric on the retina for many hippocampal spatial cells to respond. Instead, it is sufficient for a neuronal response to fixate on a small spot of light in some positions in space. This finding raises a number of interesting questions for future investigation. It would be of interest to know whether the neurons would respond while the monkey gazed at a position in space without a stimulus present (in, e.g., a blink task). If so, this would suggest that the position of the eye in the head was important in influencing the responses of these neurons. However, given the results of Experiment 1, in which many of the neurons were shown to encode frame-ofreference coordinates, this possibility is not very likely, and instead it would be of interest to investigate whether these neurons have responses that occur when fixation of a position in space is occurring, relatively independently of the particular eye gaze angle, the particular head rotation with respect to the body, and the body angle relative to the stimulus. The finding that some cells with spatial responses in the MPL, TCH, or MPOP task did not respond in the eye position task in Experiment 3 suggests that spatial position alone may not be sufficient to cause the cell to fire, but instead that a stimulus more effective than a fixation spot must be present in the spatial location to evoke a maximal response from some spatial cells. This appeared to be the case in Experiment 3 for 21 of the 28 cells tested.

It is important to distinguish between the "place" cells recorded in the rat (O'Keefe, 1979, 1983; McNaughton, Barnes, \& O'Keefe, 1983; O'Keefe \& Nadel, 1978) and the spatial cells described here in the monkey. For the "place" cells in the rat to fire, the animal must move through or into the responsive place in the environment. In our studies, we have required the monkey to direct his attention to particular locations in space, and we have found neurons that responded to stimuli in these positions in space, in the majority of cases using frame-of-reference encoding, but in some cases absolute allocentric or egocentric encoding. For these reasons, we have chosen to call the cells described here "space" cells. It will be of interest in future studies to investigate whether there are neurons in the primate hippocampus that fire when the animal visits or passes through a place in the environment, and there is preliminary evidence for this. Ono, Nakamura, Tamura, and Fukuda (1989) have found cells that appear to respond to particular locations in space as the monkey moves itself around a chamber.

In conclusion, the main finding described here is that, in the primate hippocampus, many spatial cells ( $46 \%$ of those analyzed) respond in relation to allocentric coordinates, in many cases in relation to a local frame of reference, and in some cases in relation to the absolute position of the stimulus in the room.

\section{REFERENCES}

Aggleton, J. P., Passingham, R. E. (1981). Stereotaxic surgery under $\mathrm{X}$-ray guidance in the Rhesus monkey, with special reference to the amygdala. Experimental Brain Research, 44, 271-276.

ANDERSEN, R. A. (1987). Inferior parietal lobule function in spatial perception and visuomotor integration. Handbook of Physiology: Section 1. The Nervous System: Vol. 5. Higher Functions of the Brain (Pt. 2, pp. 483-518). Washington, DC: American Physiological Society.

BARNes, C. A. (1988). Spatial learning and memory processes: The search for their neurobiological mechanisms in the rat. Trends in Neurosciences, 11, 163-169.

Bruning, J. L., KINTz, B. L. (1977). Computational handbook of statistics (2nd ed.). Glenview, IL: Scott, Foresman.

Cahusac, P. M. B., Miyashita, Y., \& Rolls, E. T. (1989). Responses of hippocampal neurons in the monkey related to delayed spatial response and object-place memory tasks. Behavioural Brain Research, 33, 229-240.

Feigenbaum, J., Cahusac, P. M. B., Rolls, E. T. (1987). The coding of spatial information by neurons in the primate hippocampal formation. Society for Neuroscience Abstracts, 13, 608.

GAFFAN, D. (1974). Recognition impaired and association intact in the memory of monkeys after transection of the fornix. Journal of Comparative \& Physiological Psychology, 86, 1100-1109.

GafFan, D. (1977). Monkey's recognition memory for complex pictures and the effects of fornix transection. Quarterly Journal of Experimental Psychology, 29, 505-514.

Gaffan, D., Gaffan, E. A., \& Harrison, S. (1984). Effects of fornix transection on spontaneous and trained non-matching by monkeys. Quarterly Joumal of Experimental Psychology, 36B, 285-303.

GAFFAN, D. \& HARRISON, S. (1989a). A comparison of the effects of fornix section and sulcus principalis ablation upon spatial learning by monkeys. Behavioural Brain Research, 31, 207-220.

GAFFAN, D., HARRISON, S. (1989b). Place memory and scene memory: Effects of fornix transection in the monkey. Experimental Brain Research, 74, 202-212.

GAFFAN, D., SAUNDERS, R. C. (1985). Running recognition of configural stimuli by fornix transected monkeys. Quarterly Journal of Experimental Psychology, 37B, 61-71. 
Gaffan, D., Saunders, R. C., Gaffan, E. A., Harrison, S., SHIELDS, C., OWEN, M. J. (1984). Effects of fornix transection upon associative memory in monkeys: Role of the hippocampus in learned action. Quarterly Journal of Experimental Psychology, 26B, 173-221.

Gaffan, D., Weiskrantz, L. (1980). Recency effects and lesion effects in delayed non-matching to randomly baited samples by monkeys. Brain Research, 196, 373-386.

Judge, S. J., Richmond, B. J., \& ChU, F. C. (1980). Implantation of magnetic search coils for measurement of eye position: An improved method. Vision Research, 20, 535-538.

McNaughton, B. L., Barnes, C. A., \& O'Keefe, J. (1983). The contributions of position, direction, and velocity to single unit activity in the hippocampus of freely-moving rats. Experimental Brain Research, 52, 41-49.

MERRILL, E. G., AINSWORTH, A. (1972). Glass-coated platinum-plated tungsten microelectrodes. Medical \& Biological Engineering, 10, 662-672.

MiLES, R. (1988). Plasticity of recurrent excitatory synapses between CA3 hippocampal pyramidal cells. Society for Neuroscience Abstracts, 14, 19.

Milner, B. (1972). Disorders of learning and memory after temporal lobe lesions in man. Clinical Neurosurgery, 19, 421-446.

Miyashita, Y., Rolls, E. T., Cahusac, P. M. B., Niki, H., \& Feigenbaum, J. D. (1989). Activity of hippocampal formation neurons in the monkey related to a conditional spatial response task. Journal of Neurophysiology, 61, 669-678.

Morris, R. G. M., Garrud, P., Rawlins, J. N. P., \& O'Keefe, J. (1982). Place navigation impaired in rats with hippocampal lesions. Nature, 297, 681-683.

O'Keefe, J. (1979). A review of the hippocampal place cells. Progress in Neurobiology, 13, 419-439.

O'KEEFE, J. (1983). Spatial memory within and without the hippocampal system. In W. Seifert (Ed.), Neurobiology of the hippocampus (pp. 375-403). London: Academic Press.

O'KeEFE, J., \& NADEL, L. (1978). The hippocampus as a cognitive map. Oxford, England: Oxford University Press (Clarendon Press).

Olton, D. S., Wible, C. G., PANG, K., Sakurai, Y. (1989). Hippocampal cells have mnemonic correlates as well as spatial ones. Psychobiology, 17, 228-229.

Ono, T., Nakamura, K., Tamura, R., \& Fukuda, M. (1989). Spatial memory related neuronal activity in monkey hippocampus. Society for Neuroscience Abstracts, 15,81 .

OWEN, M. J., BUTLER, S. R. (1981). Amnesia after transection of the fornix in monkeys: Long-term memory impaired, short-term memory intact. Behavioural Brain Research, 3, 115-123.

Parkinson, J. K., Murray, E. A., \& Mishkin, M. (1988). A selective mnemonic role for the hippocampus in monkeys: Memory for the location of objects. Journal of Neurascience, 8, 4059-4167.

Petrides, M. (1985). Deficits on conditional associative-learning tasks after frontal- and temporal-lobe lesions in man. Neuropsychologia, 23, 601-614.

RoLLS, E. T. (1987). Information representation, processing and storage in the brain: Analysis at the single neuron level. In J.-P. Changeux \& M. Konishi (Eds.), The neural and molecular bases of learning (pp. 503-540). Chichester, U.K.: Wiley.

RoLLs, E. T. (1989a). Functions of neuronal networks in the hippocampus and neocortex in memory. In J. H. Byrne \& W. O. Berry (Eds.), Neural models of plasticity: Experimental and theoretical approaches (pp. 240-265). San Diego, CA: Academic Press.

RoLls, E. T. (1989b). The representation and storage of information in neuronal networks in the primate cerebral cortex and hippocampus. In R. Durbin, C. Miall, \& G. Mitchison (Eds.), The computing neuron (pp. 125-159). Wokingham, U.K.: Addison-Wesley.

RoLLs, E. T. (1990). Functions of the primate hippocampus in spatial processing and memory. In D. S. Olton \& R. P. Kesner (Eds.), Neurobiology of comparative cognition (pp. 339-362). Hillsdale, NJ: Erlbaum.

Rolls, E. T., Burton, M. J., \& Mora, F. (1976). Hypothalamic neuronal responses associated with the sight of food. Brain Research, 111, 53-66.
Rolls, E. T., Cahusac, P. M. B., Feigenbaum, J. D., MiYaSHITA, Y. (in press). Responses of single neurons in the hippocampus of the macaque related to recognition memory. Experimental Brain Research.

Rolls, E. T., Miyashita, Y., Cahusac, P. M. B., Kesner, R. P., Niki, H., Feigenbaum, J., \& Bach, L. (1989). Hippocampal neurons in the monkey with activity related to the place in which a stimulus is shown. Joumal of Neuroscience, 9, 1835-1845.

Rolls, E. T., SAnghera, M. K., Roper-Hall, A. (1979). The latency of activation of neurones in the lateral hypothalamus and substantia innominata during feeding in the monkey. Brain Research, 164, 121-135.

RUPNIAK, N. M. J., \& GAFFAN, D. (1987). Monkey hippocampus and learning about spatially directed movements. Journal of Neuroscience, 7, 2331-2337

SakatA, H. (1985). The parietal association cortex: Neurophysiology. In M. Swash \& C. Kennard (Eds.), The scientific basis of clinical neurology (pp. 225-236). London: Churchill Livingstone.

Schwartz, E. L., Desimone, R., Alaright, T. D., Gross, C. G. (1983). Shape recognition and inferior temporal neurons. Proceedings of the National Academy of Sciences, 80, 5776-5778.

SCoviLLE, W. B., MiLNER, B. (1957). Loss of recent memory after bilateral hippocampal lesions. Joumal of Neurology, Neurosurgery, \& Psychiatry, 20, 11-21.

SMITH, M. L., MiLNer, B. (1981). The role of the right hippocampus in the recall of spatial location. Neuropsychologia, 19, 781-793.

SOKAL, R. F., RoHLF, F. J. (1981). Biometry: The principles and practice of statistics in biological research (2nd ed.). New York: W. H. Freeman.

Squire, L. R., \& Zola-Morgan, S. (1988). Memoty: Brain systems and behavior. Trends in Neurosciences, 11, 170-175.

Tamura, R., Ono, T., Fukuda, M., \& Nakamura, K. (1990). Recognition of egocentric and allocentric visual and auditory space by neurons in the hippocampus of monkeys. Neuroscience Letters, 109 , 293-298

TREVES, A. (1990). Graded-response neurons and information encodings in autoassociative memories. Physical Review, A42, 24182430.

Treves, A., Rolts, E. T. (1990). Neuronal networks in the hippocampus involved in memory. In Neural networks: Proceedings of the XI Sitges Conference. Berlin: Springer.

VAN HoEsen, G. W. (1982). The parahippocampal gyrus: New observations regarding its cortical connections in the monkey. Trends in Neurosciences, 5, 345-350.

WoOdWARD, R. H., \&oldsmith, P. L. (1964). Cumulative sum techniques: Mathematical and statistical techniques for industry (ICI Monograph No. 3). Edinburgh: Oliver and Boyd.

Zola-Morgan, S., \& Squire, L. R. (1985). Medial temporal lesions in monkeys impair memory in a variety of tasks sensitive to human amnesia. Behavioral Neuroscience, 99, 22-34.

\section{APPENDIX}

This appendix describes the remainder (or lack-of-fit) statistical analyses performed on the data obtained in Experiment 1. After the three one-way ANOVAs were performed on the data to test for the three spatial hypotheses, the remainder analyses described here indicated whether the remaining variance from an ANOVA was sufficiently great to indicate that the spatial hypothesis did not fit the data well. A remainder analysis was performed as follows. A fourth ANOVA was performed for all $k$ sets of data from one neuron, irrespective of their origin in spatial coordinates, to obtain the total sum of squares between all conditions, and the "pure" or residual (within-conditions) error (i.e., the total within-conditions sum of squares with $N-k$ degrees of freedom, where $N$ is the total number of firing rate measurements). (The residual mean square was the latter sum, divided by its number of degrees of freedom.) For each of the first three ANOVAs, the total between-conditions sum of squares (e.g., 
for the frame-of-reference spatial hypothesis) was then subtracted from the between-conditions sum of squares from the fourth ANOVA to yield a remainder sum of squares, with the number of degrees of freedom $f$ given by the corresponding subtraction. The remainder mean square was divided by the pure error mean square (i.e., the within-groups mean square from the fourth ANOVA) to give a variance ratio with $f$ and $N-k$ degrees of freedom. If this was statistically significant, it indicated a discrepancy of the data with respect to the particular spatial hypothesis being tested. For example, if the data had been sorted according to absolute allocentric position, and the one-way ANOVA for this data arrangement was significant and there was no significant remainder, then this indicated that the absolute allocentric hypothesis fit the data. Such a procedure was performed for each different spatial hypothesis.

An example of this procedure is provided in Table A1. There were 12 different sets of data collected for the different positions of the monkey, the screen, and the position of the stimulus on the screen. For this neuron, the absolute allocentric hypothesis fit the data (as shown by the significant result in the one-way ANOVA and the nonsignificant remainder), and the frame-of-reference and egocentric spatial hpotheses did not fit the data (as shown by the significant remainders).
Table A1

\begin{tabular}{|c|c|c|c|c|c|}
\hline $\begin{array}{c}\text { Source } \\
\text { of Variance }\end{array}$ & $\begin{array}{l}\text { Sum of } \\
\text { Squares }\end{array}$ & $d f$ & $\begin{array}{c}\text { Mean } \\
\text { Squares }\end{array}$ & $F$ & $p$ \\
\hline \multicolumn{6}{|c|}{$\begin{array}{l}\text { Fourth ANOVA Over } 12 \text { Sets of Data to Obtain Pure Error } \\
\text { (Residual Mean Square) }\end{array}$} \\
\hline $\begin{array}{l}\text { Between groups } \\
\text { Pure error }\end{array}$ & $1,265.16$ & $\begin{array}{r}11 \\
148\end{array}$ & 32.61 & & \\
\hline \multicolumn{6}{|c|}{ Absolute Allocentric Spatial Hypothesis } \\
\hline $\begin{array}{l}\text { Between groups } \\
\text { (in one-way }\end{array}$ & & & & & \\
\hline ANOVA) & $1,096.12$ & 9 & 121.79 & $3.66(9,150)$ & 0.006 \\
\hline Remainder & 169.04 & 2 & 84.52 & $2.59(2,148)$ & 0.08 \\
\hline \multicolumn{6}{|c|}{ Frame-of-Reference Spatial Hypothesis } \\
\hline $\begin{array}{l}\text { Between groups } \\
\text { (in one-way }\end{array}$ & & & & & \\
\hline ANOVA) & 350.13 & 3 & 116.71 & $3.17(3,156)$ & 0.03 \\
\hline Remainder & 915.04 & 8 & 114.38 & $3.51(8,148)$ & 0.001 \\
\hline \multicolumn{6}{|c|}{ Egocentric Spatial Hypothesis } \\
\hline $\begin{array}{l}\text { Between groups } \\
\text { (in one-way }\end{array}$ & & & & & \\
\hline $\begin{array}{l}\text { ANOVA) } \\
\text { Remainder }\end{array}$ & $\begin{array}{l}533.2 \\
731.96\end{array}$ & $\begin{array}{l}5 \\
6\end{array}$ & $\begin{array}{l}106.2 \\
121.99\end{array}$ & $\begin{array}{l}2.95(5,154) \\
3.74(6,148)\end{array}$ & $\begin{array}{l}0.01 \\
0.002\end{array}$ \\
\hline
\end{tabular}

